\title{
AMPA-Kainate Receptor Inhibition Promotes Neurologic Recovery in Premature Rabbits with Intraventricular Hemorrhage
}

\author{
Preeti Dohare, ${ }^{1}$ Muhammad T. Zia, ${ }^{1,2}$ Ehsan Ahmed, ${ }^{1}$ Asad Ahmed, ${ }^{1}$ Vivek Yadala, ${ }^{1}$ Alexandra L. Schober, ${ }^{3}$ \\ Juan Alberto Ortega, ${ }^{4}$ Robert Kayton, ${ }^{5}$ Zoltan Ungvari, ${ }^{6}$ Alexander A. Mongin, ${ }^{3}$ and Praveen Ballabh ${ }^{1,2}$ \\ Departments of ${ }^{1}$ Pediatrics and ${ }^{2}$ Cell Biology and Anatomy, Regional Neonatal Center, Maria Fareri Children's Hospital at Westchester Medical Center-New \\ York Medical College, Valhalla, New York 10595, ${ }^{3}$ Center for Neuropharmacology and Neuroscience, Albany Medical College, Albany, New York 12208 , \\ ${ }^{4}$ Department of Neuroscience, University of Connecticut Health Center, Farmington, Connecticut 06030, ${ }^{5}$ Department of Physiology and Pharmacology, \\ Oregon Health and Science University, Portland, Oregon 97239, and 6Reynolds Oklahoma Center on Aging, and Department of Geriatric Medicine, \\ University of Oklahoma Health Science Center, Oklahoma City, Oklahoma 73104
}

Intraventricular hemorrhage (IVH) in preterm infants leads to cerebral inflammation, reduced myelination of the white matter, and neurological deficits. No therapeutic strategy exists against the IVH-induced white matter injury. AMPA-kainate receptor induced excitotoxicity contributes to oligodendrocyte precursor cell (OPC) damage and hypomyelination in both neonatal and adult models of brain injury. Here, we hypothesized that IVH damages white matter via AMPA receptor activation, and that AMPA-kainate receptor inhibition suppresses inflammation and restores OPC maturation, myelination, and neurologic recovery in preterm newborns with IVH. We tested these hypotheses in a rabbit model of glycerol-induced IVH and evaluated the expression of AMPA receptors in autopsy samples from human preterm infants. GluR1-GluR4 expressions were comparable between preterm humans and rabbits with and without IVH. However, GluR1 and GluR2 levels were significantly lower in the embryonic white matter and germinal matrix relative to the neocortex in both infants with and without IVH. Pharmacological blockade of AMPA-kainate receptors with systemic NBQX, or selective AMPA receptor inhibition by intramuscular perampanel restored myelination and neurologic recovery in rabbits with IVH. NBQX administration also reduced the population of apoptotic OPCs, levels of several cytokines (TNF $\alpha, I L-\beta, I L-6, L I F)$, and the density of $\mathrm{Ibal}^{+}$microglia in pups with IVH. Additionally, NBQX treatment inhibited STAT-3 phosphorylation, but not astrogliosis or transcription factors regulating gliosis. Our data suggest that AMPA-kainate receptor inhibition alleviates OPC loss and IVH-induced inflammation and restores myelination and neurologic recovery in preterm rabbits with IVH. Therapeutic use of FDA-approved perampanel treatment might enhance neurologic outcome in premature infants with IVH.

Key words: AMPA; myelination; NBQX; oligodendrocyte; perampanel

Significance Statement

Intraventricular hemorrhage (IVH) is a major complication of prematurity and a large number of survivors with IVH develop cerebral palsy and cognitive deficits. The development of IVH leads to inflammation of the periventricular white matter, apoptosis and arrested maturation of oligodendrocyte precursor cells, and hypomyelination. Here, we show that AMPA-kainate receptor inhibition by NBQX suppresses inflammation, attenuates apoptosis of oligodendrocyte precursor cells, and promotes myelination as well as clinical recovery in preterm rabbits with IVH. Importantly, AMPA-specific inhibition by the FDA-approved perampanel, which unlike NBQX has a low side-effect profile, also enhances myelination and neurological recovery in rabbits with IVH. Hence, the present study highlights the role of AMPA-kainate receptor in IVH-induced white matter injury and identifies a novel strategy of neuroprotection, which might improve the neurological outcome for premature infants with IVH. 


\section{Introduction}

Intraventricular hemorrhage (IVH) remains the most common neurological complication of prematurity that results in neurodevelopmental consequences, including cerebral palsy, cognitive deficits, and mental retardation (Ballabh, 2010). No therapeutic or preventive strategy exists for the white matter injury in premature infants with IVH. Because AMPA-kainate receptor activation reduces myelination in several paradigms of brain injury (Fern and Möller, 2000; Deng et al., 2003; Follett et al., 2004; Kanwar et al., 2004), we asked whether AMPA-kainate glutamate receptor stimulation would induce white matter injury in survivors with IVH.

IVH develops predominantly in preterm infants of 22-32 gestational weeks. During this period, oligodendrocyte progenitor cells (OPCs) are in a process of specification and maturation. Three successive stages of oligodendrocytes have been identified, including the late OL progenitor (preoligodendrocytes), the immature OL, and the mature OL. Preoligodendrocytes (premyelinating cells) are the most abundant in preterm infants of 22-32 gestational weeks, and myelinating (immature OPCs) oligodendrocytes are progressively increasing in number after 28-32 gestational weeks (Back et al., 2001). Preoligodendrocytes are more vulnerable to hypoxia-ischemia and glutamate receptormediated toxicity compared with myelinating OPCs (Fern and Möller, 2000; Back et al., 2002; Itoh et al., 2002; Deng et al., 2003). These OPCs are known to express AMPA (glutamate receptors 1-4 [GluR1-GluR4]) and kainate (GluR5-GluR7 and KA1-2) receptors (Gallo et al., 1994; Rosenberg et al., 2003). AMPA receptors are tetrameric ligand-gated ion channels located on the postsynaptic membrane that mediate glutamatergic excitatory transmission. The presence of GluR2 subunits renders AMPA receptors impermeable to calcium ions (Verdoorn et al., 1991; Geiger et al., 1995). All the GluR subtypes are expressed in OPCs; however, their expressions vary during development and with brain region (Fern and Möller, 2000; Rosenberg et al., 2003). The presence of GluR1, GluR3, and GluR4 subunits makes particularly OPCs susceptible to excitotoxic damage during development because $\mathrm{Ca}^{2+}$ influx through these receptors triggers a cascade of injury.

A number of studies have evaluated AMPA receptors in models of hypoxia-ischemia, cerebral trauma, and multiple sclerosis and have reported neuroprotection with blockade of AMPAkainate receptors (Pulsinelli et al., 1982; Choi, 1995; Tanaka et al., 2000; Goda et al., 2002; Groom et al., 2003). Global hypoxiaischemia reduces both mRNA and protein expression of GluR2 subunit, and this reduction enhances $\mathrm{Ca}^{2+}$ permeability of AMPA receptors in neurons and glia during the insult (Pellegrini-Giampietro et al., 1992). Moreover, glutamate accumulates in perisynaptic spaces under hypoxic-ischemic conditions, thereby activating AMPA receptors and eliciting glutamate excitotoxicity. Rodent OPCs primarily express AMPA and kainate receptors, but not the NMDA receptors (Gallo et al., 1994; Rosenberg et al., 2003). Indeed, AMPA-kainate receptor antago-

\footnotetext{
Received Nov. 30, 2015; revised Feb. 5, 2016; accepted Feb. 5, 2016.

Author contributions: P.B. designed research; P.D., M.T.Z., E.A., A.A., V.Y., A.L.S., J.A.O., R.K., Z.U., and P.B. performed research; P.D. and P.B. analyzed data; A.A.M. and P.B. wrote the paper.

This work was supported by National Institutes of Health/National Institute of Neurological Disorders and Stroke Grant 1R01NS083947-01 to P.B.

The authors declare no competing financial interests.

Correspondence should be addressed to Dr. Praveen Ballabh, Regional Neonatal Center, Maria Fareri Children's Hospital at Westchester Medical Center, Valhalla, NY 10595. E-mail: Pballabh@msn.com.

DOI:10.1523/JNEUROSCI.4329-15.2016

Copyright $\odot 2016$ the authors $\quad 0270-6474 / 16 / 363364-15 \$ 15.00 / 0$
}

nists inhibit calcium mediated excitotoxicity and cell death in OPC culture model of oxygen-glucose deprivation (Fern and Möller, 2000; Yoshioka et al., 2000; Deng et al., 2003). Consistent with this, NBQX, an AMPA-kainate receptor antagonist, treatment restores myelination in a neonatal rat model of hypoxiaischemia (Follett et al., 2004). More importantly, glutamate excitotoxicity is thought to be a major contributor to hypomyelination in human preterm infants (Volpe, 2009a). Despite this, the role of glutamate excitotoxicity in IVH-induced white matter injury and therapeutic benefits of AMPA-kainate receptor inhibition in restoring myelination have remained unexplored.

Our previous studies have shown that IVH induces robust inflammation in the periventricular white matter, leading to microglial infiltration, oxidative stress, and elevation in proinflammatory cytokines, TNF $\alpha$, IL- $1 \beta$, and astrogliosis (Georgiadis et al., 2008; Chua et al., 2009; Vinukonda et al., 2010). JAK-STAT signaling are key regulators of inflammation and cell survival. STAT3 is expressed by both oligodendrocytes and astrocytes in the CNS (Cattaneo et al., 1999) and is involved in the astrocytic differentiation and astrogliosis (Herrmann et al., 2008). Based on these considerations, we hypothesized that IVH would activate AMPA receptors and that AMPA-kainate (NBQX) or AMPA (perampanel) receptor inhibition might suppress inflammation and restore OPC maturation, myelination as well as clinical recovery in preterm rabbit pups with IVH. We also postulated that NBQX treatment might reduce astrogliosis through inhibition of JAK-STAT signaling.

\section{Materials and Methods}

Animals. This study was performed with approval from the Institutional Animal Care and Use Committee of New York Medical College (Valhalla, NY). We used a preterm rabbit model of glycerol-induced IVH that has been extensively validated in our prior studies (Chua et al., 2009; Vinukonda et al., 2010; Vose et al., 2013). Timed-pregnant New Zealand rabbits were purchased from Charles River Laboratories. We performed $\mathrm{C}$-section to deliver the premature pups at $29 \mathrm{~d}$ of gestational age (fullterm $=32 \mathrm{~d}$ ). Newborn pups were reared in an infant incubator at a temperature of $35^{\circ} \mathrm{C}$. We used rabbit milk replacer (Zoologic, PetAg) to gavage-feed the pups in a volume of $\sim 2 \mathrm{ml}$ every $12 \mathrm{~h}(100 \mathrm{ml} / \mathrm{kg} / \mathrm{d})$ for the first $2 \mathrm{~d}$, and feeds were advanced to $125,150,200,250$, and $280 \mathrm{ml} / \mathrm{kg}$ at postnatal days $3,5,7,10$, and 14 , respectively. We treated rabbit pups of either sex with $50 \%$ intraperitoneal glycerol $(6.5 \mathrm{~g} / \mathrm{kg})$ at $4 \mathrm{~h}$ of age to induce IVH. Severity of IVH was evaluated by measuring ventricle volume (length, breadth, and depth in coronal and sagittal views) on head ultrasound at $24 \mathrm{~h}$ age using an Acuson Sequoia C256 (Siemens) ultrasound machine. Pups with IVH were grouped as moderate (70-150 $\mathrm{mm}^{3}$ ) and severe (151-250 $\mathrm{mm}^{3}$ ) IVH, based on ventricular volume (see Fig. 1A). Ventricular volume $<70 \mathrm{~mm}^{3}$ indicated either an absence of IVH or presence of microscopic hemorrhage. Intraperitoneal glycerol induces intraventricular hemorrhage by causing intravascular dehydration, increase in serum osmolality, consequent decline in intracranial pressure, and rupture of fragile vessels in the ganglionic eminence (Ballabh et al., 2007; Georgiadis et al., 2008). The pups with moderate and severe IVH were assigned into treatment and control group so that the severity of IVH was balanced between the comparison groups.

$N B Q X$ and perampanel treatment. The rabbit pups with IVH were sequentially treated with either intramuscular vehicle (saline) or NBQX $(20 \mu \mathrm{l}, 15 \mathrm{mg} / \mathrm{kg}$ ) twice a day for $7 \mathrm{~d}$, starting at day 1 . The dose of NBQX was calculated based on its previous use in a rodent model of hypoxiaischemia rats and in other models of cerebral injury (Jackson et al., 1998; Jensen, 2005). The severity of IVH, measured by ultrasound, was similar between the comparison groups: vehicle-treated pups with IVH and NBQX-treated pups with IVH. In another set of experiments, rabbit pups with moderate to severe IVH were sequentially treated with intramuscular perampanel $(8 \mathrm{mg} / \mathrm{kg})$ or saline once daily. The dose of perampanel was based on its previous use in animal model and human clinical trials 
Table 1. Characteristics of human infants with and without IVH

\begin{tabular}{lllll}
\hline $\begin{array}{l}\text { Postconceptional } \\
\text { age (weeks) }\end{array}$ & Sex & $\begin{array}{l}\text { Birth } \\
\text { weight }(\mathrm{kg})\end{array}$ & IVH/no IVH & Cause of death \\
\hline 26 & Male & 0.810 & IVH Grade 3 & Clinical sepsis \\
23 & Male & 0.57 & IVH Grade 2 & Clinical sepsis \\
23 & Female & 0.58 & IVH Grade 3 & Respiratory failure \\
24 & Male & 0.64 & IVH Grade 4 & Pulmonary \\
& & & & hemorrhage \\
24 & Male & 0.6 & IVH Grade 4 & Clinical sepsis \\
23 & Female & 0.52 & IVH Grade 3 & Respiratory failure \\
23 & Female & 0.53 & No IVH & Respiratory failure \\
25 & Female & 0.71 & No IVH & Metabolic acidosis, \\
& & & & respiratory failure \\
23 & Male & 0.45 & No IVH & RDS, respiratory \\
& & & & failure \\
24 & Male & 0.61 & No IVH & Clinical sepsis \\
24 & Male & 0.73 & No IVH & Metabolic acidosis, \\
& & & & respiratory failure \\
& Female & 0.56 & No IVH & Respiratory failure \\
\hline
\end{tabular}

RDS, Respiratory distress syndrome.

(Russo et al., 2012; Hanada et al., 2014). Rectal temperature was monitored for the pups during the first $3 \mathrm{~d}$ using rectal probe.

Human subjects. The Research Administration of New York Medical College (Valhalla, NY) approved the use of autopsy brain samples from premature infants for the present study. The postmortem materials included forebrain tissue samples harvested from premature infants with and without IVH of 23-26 gestational weeks. These infants were of $<5 \mathrm{~d}$ of postnatal age (Table 1), and the postmortem samples were obtained within $18 \mathrm{~h}$ of their demise. We excluded premature neonates with hypoxic-ischemic encephalopathy, meningitis, culture proven sepsis, major brain or spinal cord malformation, and chromosomal defects. We included 6 preterm infants from each group (IVH and no IVH). The wall of the cerebral hemisphere in premature infants consists of ventricular zone, subventricular zone, intermediate zone, cortical plate, and marginal zone as illustrated by the Boulder Committee (Bystron et al., 2008). In this manuscript, we used the term intermediate-zone embryonic white matter interchangeably with white matter, ganglionic eminence with germinal matrix, and cerebral cortex with cortical plate.

Rabbit tissue collection and processing. We processed the tissues as described previously (Ballabh et al., 2007). The brain slices were immersed into $4 \%$ PFA in PBS (0.1 M, pH 7.4) overnight and then were cryoprotected by keeping them into $15 \%$ sucrose in $0.1 \mathrm{~m}$ PBS buffer for $24 \mathrm{~h}$ followed by $30 \%$ sucrose for the next $24 \mathrm{~h}$. We then froze the tissue slice after embedding into optimum cutting temperature compound (Sakura). Frozen coronal blocks were cut on a cryostat into coronal sections of $20 \mu \mathrm{m}$ thickness. For Western blot analyses, 1- to 2-mm-thick coronal slice was harvested at the level of the midseptal nucleus and snap-frozen on dry ice.

Human tissue collection and processing. We processed the human tissues as in our previous studies (Ballabh et al., 2007). Coronal slices of 3-4 $\mathrm{mm}$ thickness were taken at the level of head of caudate nucleus from the frontoparietal lobe. The coronal blocks consisted of cortical plate, embryonic white matter, and ganglionic eminence. The samples were immersion-fixed into 4\% PFA in PBS for 12-18 h and were then cryoprotected by immersing into a $15 \%$ sucrose solution in PBS, followed by $30 \%$ sucrose in PBS. The tissues were next frozen after embedding them into optimum cutting temperature compound (Sakura). Frozen coronal blocks were cut into sections of $20 \mu \mathrm{m}$ thickness. For Western blot analyses, pieces of tissues were directly harvested from the cortex, white matter, and ganglionic eminence into Eppendorf tubes and were snap-frozen on dry ice.

Immunohistochemistry. Immunohistochemical staining was performed as described previously (Ballabh et al., 2007). The primary antibodies used in experiments included the following: rabbit GluR1 (catalog \#13185, Cell Signaling), rabbit GluR2 (catalog \#ab1506, Millipore), rabbit GluR3 (catalog \#4676, Cell Signaling), rabbit GluR4 (catalog \#8070,
Cell Signaling), goat polyclonal Ki67 (catalog \#275R-14, Cell Marque), goat polyclonal Olig2 (catalog \#AF-2418, R\&D Systems), mouse monoclonal GFAP (catalog \#G6171, Sigma-Aldrich), mouse monoclonal myelin basic protein (MBP; catalog \#ab62631, Abcam), goat polyclonal PDGFR $\alpha$ (catalog \#AR307, R\&D Systems), mouse monoclonal myelinassociated glycoprotein (MAG; catalog \#AB89780, Abcam), mouse monoclonal Stat 3 (catalog \#9139, Cell Signaling Technology), rabbit pStat3 (tyrosine 705, catalog \#9145, Cell Signaling Technology), mouse pStat3 (serine 727, catalog \#9136, Cell Signaling Technology), mouse NKX2.2 (Developmental Studies Hybridoma Bank, University of Iowa), goat Iba1 (catalog \#5076, Abcam), rabbit polyclonal NFIA (catalog \#39397, Active Motif), rabbit polyclonal Sox9 (catalog \#ab5535, Millipore), and sheep polyclonal Notch intracellular domain (NICD) (catalog \#AF3647, R\&D Systems). Secondary antibodies used were Cy-3 conjugate donkey anti-mouse, Cy-3 conjugate donkey anti-goat, and FITC conjugate donkey anti-rat (Jackson ImmunoResearch Laboratories). Briefly, we hydrated the fixed sections in $0.1 \mathrm{~m}$ PBS, blocked the sections with normal donkey serum in PBS with $0.01 \%$ Triton-X (PBST), and incubated with the primary antibodies diluted in PBST at $4^{\circ} \mathrm{C}$ overnight. After several washes in PBS, the sections were incubated with secondary antibody diluted in 1\% normal goat serum in PBS at room temperature for 60 min. Finally, after washing in PBS, sections were mounted with Slow Fade Light Antifade reagent (Invitrogen) and were visualized under a Confocal microscope (Nikon Instruments). Stereology was performed using a fluorescent microscope (Axioskop 2 plus, Carl Zeiss) with motorized specimen stage for automated sampling (ASI), CCD color video camera (Microfire, Optronics), and stereology software (Stereologer, SRC).

Fluorescent in situ detection of DNA fragmentation (TUNEL). We performed TUNEL staining on fixed brain sections as described previously (Dummula et al., 2011). For TUNEL staining, tissue sections of $12 \mu \mathrm{m}$ thickness were air dried on slides, hydrated in $0.01 \mathrm{M} \mathrm{PBS}$, and permeabilized for $5 \mathrm{~min}$ in 1:1 ethanol/acetic acid. An ApopTag-fluorescein in situ DNA fragmentation detection kit (catalog \#S7110, Millipore) was used to visualize TUNEL-labeled nuclei.

Quantification of oligodendrocytes. Proliferation and maturation of OPCs were assessed in the corona radiata and corpus callosum of pups without IVH and pups with IVH treated with vehicle or NBQX. Cycling OLs were identified by double-labeling the coronal sections with Olig2 and Ki67 antibodies, whereas maturation of OLs was evaluated by double-labeling the sections with Olig2 and Nkx2.2 antibodies. All coronal sections were obtained at the level of the midseptal nucleus (five 20 $\mu \mathrm{m}$ sections collected at $60 \mu \mathrm{m}$ interval). Quantification was performed by a blinded investigator in a random, unbiased fashion using a confocal microscope with a $60 \times$ lens (Nikon Instruments). Cells were counted in $\sim 25$ images ( 5 images $\times 4-5$ sections) for each brain region for every parameter for each pup ( $n=5$ pups per group).

Stereological assessment of myelin and astrocytes in the white matter. We quantified a number of stereological parameters using computerized software system (Stereologer, Stereology Resource Center). Briefly, 30$\mu \mathrm{m}$-thick coronal sections were cut on a cryostat with a section sampling interval of $90 \mu \mathrm{m}$ to achieve $\geq 6$ sections at the level of mid-septal nucleus. The sections were double-labeled with MBP antibody and DAPI (nuclear stain) and quantified as follows. The reference spaces (corona radiata, corpus callosum) were outlined on the section $<5 \times$ objective. The volume of the outlined area (reference space) was quantified using a point counting probe (frame $25 \mu \mathrm{m} \times 25 \mu \mathrm{m}$; guard zone $2 \mu \mathrm{m}$, interframe interval $=300 \mu \mathrm{m}$ ). The total volume fraction (load) of myelin stained by MBP antibody through a defined reference space was estimated using the object area fraction probe $<60 \times$ oil lens. For the area fraction probe (frame $25 \mu \mathrm{m} \times 25 \mu \mathrm{m}$; guard zone $2 \mu \mathrm{m}$, interframe interval $400 \mu \mathrm{m}$ ), the user clicked on the grid points that overlapped the myelin fibers in sections labeled with MBP. The area fraction of myelination was quantified as the ratio of product of the area per point and number of points hitting reference area the over the product of the area per point and number of points hitting the sampled area $[\mathrm{a}$ (point). $\left.\sum \mathrm{P}_{\text {samp }}\right]$, as reported previously. A coefficient of error $<0.10$ was considered acceptable. To assess gliosis, we quantified total volume fraction of astrocyte cell body and glial fibers in a similar manner as for myelin (Mouton et al., 2009). 
Western blot analyses. We homogenized the frozen brain tissue in a sample buffer (3\% SDS, $10 \%$ glycerol, and $62.5 \mathrm{~mm}$ Tris- $\mathrm{HCl}$ ) using a mechanical homogenizer and then sonicated the lysate before centrifugation. Supernatant protein concentration was measured using a BCA protein assay kit (Pierce, kit \#23227, Thermo Scientific), and dilutions of BSA were used to create a standard curve. After boiling the samples in Laemmli buffer (catalog \#161-0737, Bio-Rad), total protein samples were separated by SDS-PAGE (Vinukonda et al., 2010). Equal amounts of protein $(10-20 \mu \mathrm{g})$ were loaded onto $4 \%-15 \%$ or $4 \%-20 \%$ gradient precast gels (Bio-Rad), based on the molecular weight of the target protein. Separated proteins were transferred onto PVDF membrane by electro-transfer. Membranes were then incubated overnight with primary antibodies. We detected target proteins with chemiluminescence ECL system (GE Healthcare) by using secondary antibodies conjugated with HRP (Jackson ImmunoResearch Laboratories). We stripped the membrane using stripping buffer (2.5\% SDS, 0.7\% 2-mercaptoethanol, $62.5 \mathrm{~mm}$ Tris- $\mathrm{HCl}, \mathrm{pH} 6.8$ ) and then incubated with $\beta$-actin antibody (catalog \#A5316, Sigma) followed by secondary antibody and detection with chemiluminescence ECL system. As described previously (Vinukonda et al., 2010), the blots from each experiment were densitometrically analyzed using ImageJ, and optical density (OD) values for each protein of interest were normalized to those of $\beta$-actin. Antibodies used for Western blot analyses were the same as for immunohistochemistry.

Calcium signaling studies. OPCs were isolated from E29 rabbit brain, as described previously (Ortega et al., 2013). Briefly, whole forebrain tissue was harvested from an anesthetized rabbit pup. The brain was mechanically dissociated in $0.025 \%$ trypsin-EDTA solution. OPCs were then isolated from the homogeneous cell suspension using anti- $\mathrm{O}_{4}$ microbeads (Magnetic Activated Cell Sorting protocol, Miltenyi Biotec), and $\sim 100,000-150,000$ cells per coverslip were plated. The OPCs were cultured for $3 \mathrm{~d}$ in expansion medium at $37^{\circ} \mathrm{C}$. The cells were loaded with Fluorforte (ENZ-51017, Enzo Life Sciences) for $60 \mathrm{~min}$ at room temperature per the manufacturer's instructions. To assess AMPA-kainatemediated $\mathrm{Ca}^{2+}$ uptake, cells were incubated with NBQX $(20 \mu \mathrm{M})$ or vehicle and then were treated with plasma. After 40 min of incubation, the images were acquired at identical settings using Nikon confocal microscope, and fluorescence intensity was calculated using NIS software (Nikon).

$q R T-P C R$. Gene expression was quantified by real-time PCR, as described previously (Ballabh et al., 2007). Briefly, total RNA was isolated using a RNeasy Mini kit (catalog \#74104, QIAGEN) from a coronal brain slice taken at the level of the mid-septal nucleus. cDNA was synthesized using Superscript II RT enzyme (catalog \#05081955001, Roche) followed by a real-time quantitation using an ABI Prism 7900 HT detection system. TaqMan probes were bought from Invitrogen. Their assay IDs were as follows: GAPDH (Oc03823402_g1), GRIA1 (Hs00990746_m1), GRIA2 (Hs00968358_m1), GRIA3 (Hs01557466_m1), GRIA4 (Hs00898778_m1), TNF $\alpha$ (Oc03397716_g1), IL1 $\beta$ (Oc03823250_s1), CNTF (Oc0339 7817_m1), LIF (Hs01055668_m1), IL-6 (Oc04097053_m1), and interferon- $\gamma(\mathrm{Oc} 04096817$ m1).

Electron microscopy. We processed brains (14 d) from the glycerol treated rabbit pups without IVH, pups with IVH, and the NBQX-treated pups with IVH ( $n=3$ or 4 each). We took coronal slices ( $2 \mathrm{~mm}$ thickness) from freshly harvested rabbit pup brain using a brain slicer matrix and then dissected corona radiata and corpus callosum in a Petri dish under a SteReo discovery microscope (Carl Zeiss). The tissue samples from the white matter were fixed into $2.5 \%$ glutaraldehyde overnight. The tissue samples were then washed in $0.1 \mathrm{~m}$ sodium cacodylate buffer, $\mathrm{pH} 7.4$, postfixed in buffered osmium tetroxide for $1-2 \mathrm{~h}$, stained en bloc with $1 \%$ uranyl acetate, dehydrated in graded ethanol solutions, and then embedded in epoxy resin. We placed sections of 60-90 nm thicknesses onto 200 mesh grids, stained with uranyl acetate and lead citrate, and then examined with a Techni 12 electron microscope at $80 \mathrm{kV}$. For each brain, we acquired 12-20 digital images using a 16 megapixel camera (Advanced Microscopy Techniques). Electron micrographs were assessed for myelinated axons per unit area; and the g-ratio (ratio of axonal diameter with myelin sheath to the axonal diameter without myelin sheath) of myelinated axons were computed in the three groups of pups using ImageJ (National Institutes of Health).
HPLC analysis of amino acid content in CSF samples. The CSF samples were snap-frozen on dry ice and stored at $-80^{\circ} \mathrm{C}$ until the day of HPLC assay. Samples were thawed on ice and immediately deproteinated using ice-cold methanol (1:4). After 15 min incubation on ice, samples were clarified by centrifugation $(15,000 \times g$ for $15 \mathrm{~min})$. The supernatants were removed and analyzed for amino acid content using a 1200 HPLC setup with fluorescence detector (Agilent Technologies) as previously described (Dohare et al., 2014). Briefly, the amino acid levels were quantified after derivatization with $o$-phthalaldehyde in the presence of $\beta$-mercaptoethanol. The derivatives were separated on an Eclipse XDB-C18 HPLC column, and fluorescence intensities of separated products were compared with the calibration standards of L-glutamate, L-glutamine, taurine and L-alanine.

Statistics and analysis. Data are presented as mean \pm SEM. To compare the levels of MBP, MAG, CNPase, and cytokines as well as cell counts between three groups (no IVH, vehicle, and NBQX or perampaneltreated pups), we used one-way ANOVA. To assess the difference in the protein and mRNA expression of glutamate receptors between pups with and without IVH at 24 and $72 \mathrm{~h}$ age, we used two-way ANOVA with repeated measures. Likewise, protein expression of GluR1-GluR4 in the three brain regions (cortex, white matter, and germinal matrix) in preterm infants with and without IVH was compared using two-way ANOVA with repeated measures. The repeated factor was applied to the three brain regions: ganglionic eminence, white matter, and cortex. All post hoc comparisons between means were done by Tukey multiplecomparison test at 0.05 significance.

\section{Results \\ IVH does not affect glutamate receptor expression in rabbits and humans}

To determine whether IVH affects the expression of AMPA receptor subunits, GluR1-GluR4, in premature human infants (postmortem) of 23-26 weeks gestational age, we labeled coronal sections from the forebrain with GluR1-GluR4 specific antibodies. GluR1-GluR4 were abundantly expressed in the neocortical mantle (cortex), embryonic white matter, and germinal matrix of preterm infants (data not shown). GluR1 was expressed on a number of $\mathrm{O}^{+}$OPCs in the white matter and germinal matrix, however weakly on $\mathrm{GFAP}^{+}$radial glia of the germinal matrix and astrocytes of the white matter. GluR2 reactivity was observed on both $\mathrm{O}^{+}{ }^{+} \mathrm{OPCs}$ and $\mathrm{GFAP}^{+}$astrocytes as well as on radial glia. GluR3 and GluR4 were abundantly expressed on GFAP ${ }^{+}$astrocytes and on a few $\mathrm{O}_{4}{ }^{+}$oligodendrocytes. The expression of GluR1-GluR4 was weak to absent on $\mathrm{MAP} 2{ }^{+}$neuronal progenitors in the germinal matrix; however, they were abundantly expressed on the cortical neurons. Overall, immunoreactivity of GluR1-GluR4 in the cortex, white matter, and germinal matrix was comparable between preterm infants with and without IVH. However, comparison between the brain regions revealed that GluR1-GluR2 immunoreactivity was relatively lower in the white matter and germinal matrix compared with the cortex. Western blot analyses confirmed that GluR1-GluR4 levels were similar between infants with and without IVH in the three brain regions (Fig. 1C). However, GluR1 and GluR2 were reduced in the white matter and germinal matrix compared with the cortex in both infants with IVH and without IVH $(p<0.001$, all).

We next evaluated the protein expression of GluR1-GluR4 in the forebrain of preterm rabbits (E29) with IVH versus without IVH at 48 and $72 \mathrm{~h}$ postnatal age by Western blot analyses (Fig. $2 A)$. There was no significant difference in the levels of these receptors between pups with and without IVH. Accordingly, mRNA expression of GluR1-GluR4 was comparable in the forebrain of preterm rabbits with and without IVH at both postnatal day 3 (D3) and day 7 (D7) (Fig. 2B). There was no significant interval change in the expression of these receptors. Together, the 


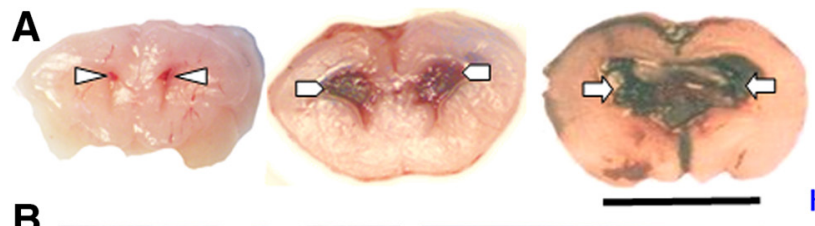

B
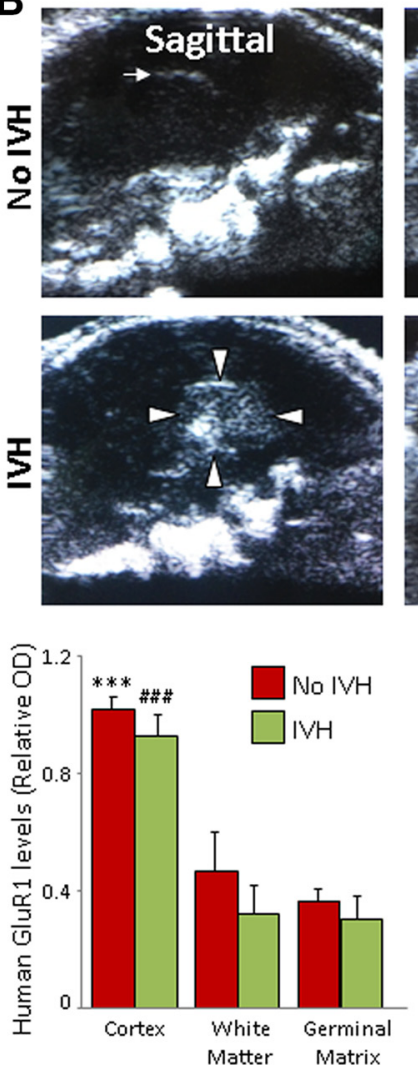
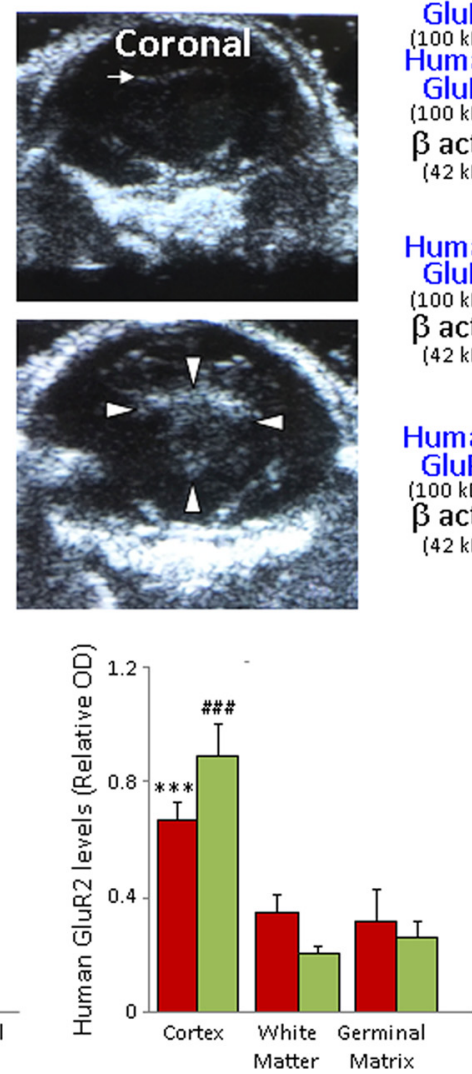

C
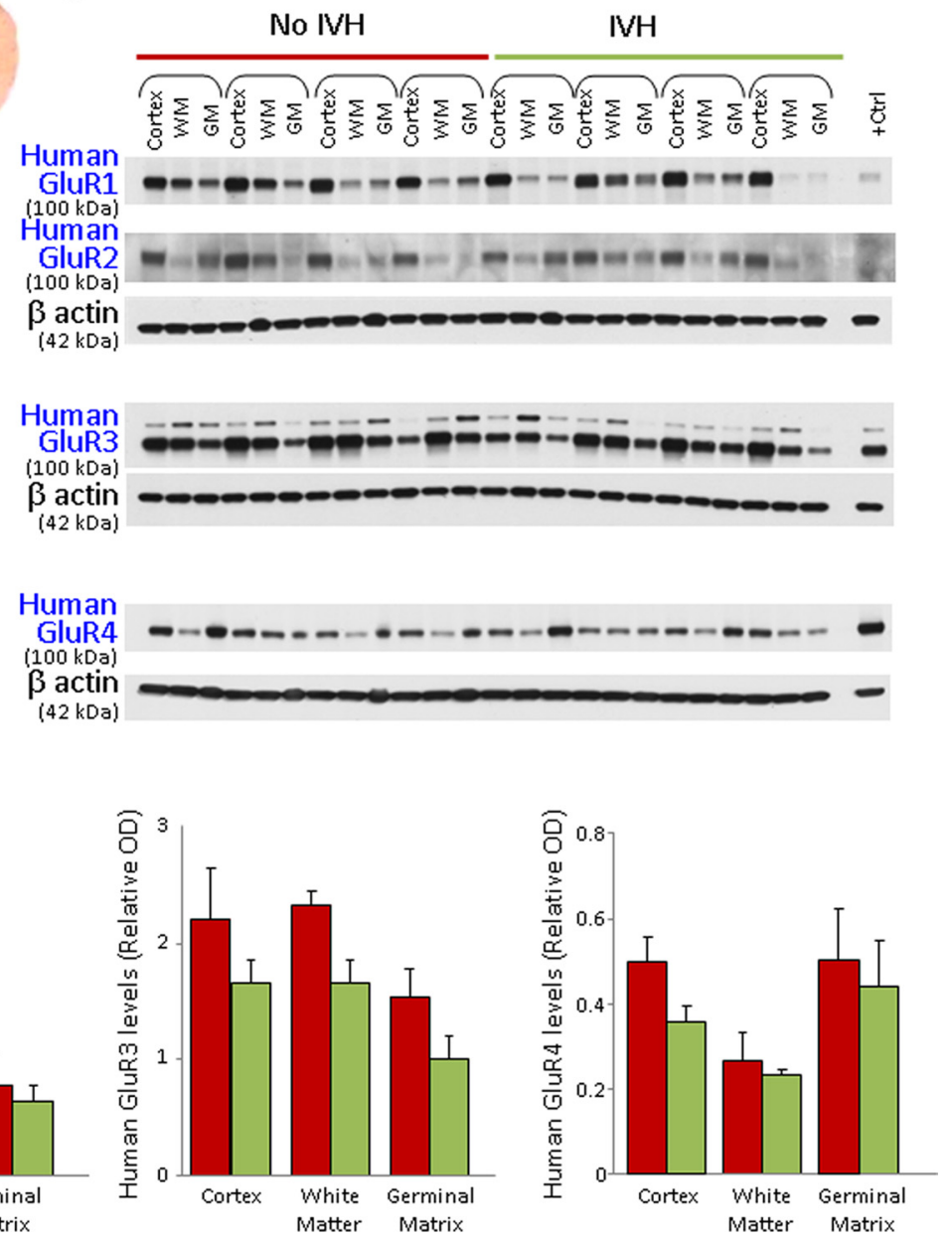

Figure 1. IVH in rabbit brains and AMPA receptor subunits in premature human infants. $\boldsymbol{A}$, Coronal brain slice taken from frontal lobe of E29 rabbit pup, which shows normal slit-like ventricle (arrowhead), moderate hemorrhage in the ventricle (middle panel), and severe hemorrhage resulting in fusion of the two ventricles (block arrows). Scale bar, $1 \mathrm{~cm}$. $\boldsymbol{B}$, Coronal and sagittal views of head ultrasound of rabbits with (bottom) and without IVH (top). Arrow indicates slit-like ventricle in pups without IVH. Arrowhead indicates large IVH. C, Western blot analysis for AMPA receptor subunits GluR1-GluR4 in the brain tissue from preterm human infants with and without IVH. Data are mean \pm SEM ( $n=5$, each group). Protein expression values were normalized to the levels of $\beta$-actin. There was no significant difference in the expression of any GluRs between infants with IVH and without IVH. There are significantly reduced levels of GluR1 and GluR2 in the germinal matrix and white matter relative to the cortex in both infants with and without IVH. ${ }^{* *} p<0.001$, cortex versus germinal matrix or white matter in infants without IVH. ${ }^{\# \# \# ~} p<0.001$, cortex versus germinal matrix or white matter in infants with IVH.

development of IVH did not affect GluR1-GluR4 expression in rabbit pups or human infants with and without IVH. However, both GluR1 and GluR2 were reduced in the periventricular germinal matrix and embryonic white matter relative to the cortex of premature infants. A reduction in GluR2 might render these brain regions more vulnerable to glutamate-induced toxicity.

\section{Glutamate levels in the CSF showed a trend toward increase in rabbits with IVH}

Glutamate has a pivotal role in neurological disorders, and its levels are increased in cerebral ischemia, trauma, and degenerations (Dávalos et al., 1997). Therefore, we postulated that glutamate might be increased in the pups with IVH. The cerebral ventricles are filled with blood in these pups with IVH, and it is gradually absorbed by days $3-5$. To avoid blood contamination in the samples and based on the feasibility in premature pups, we assayed glutamate in CSF obtained from cisterna magna puncture at D3 and D7. The glutamate levels were measured by highperformance chromatography in the CSF of (1) rabbits without IVH (no glycerol), (2) glycerol-treated rabbits without IVH, and (3) glycerol-treated rabbits with IVH. The mean levels of CSF glutamate in pups with IVH was twofold to threefold higher compared with pups without IVH (no glycerol) and approximately twofold higher relative to glycerol-treated pups without IVH (Fig. 2C). However, these comparisons were not statistically significant. The CSF levels of two major extracellular amino acids (glutamine and alanine) were similar between the three sets of pups (data not shown), suggesting specificity of observed changes in CSF glutamate. Some elevation in CSF glutamate levels in glycerol-treated pups without IVH (relative to pups without glycerol treatment) can be attributed to a failure of head ultrasound to detect microscopic bleeds. Indeed, microscopic IVH after glycerol treatment can potentially induce some increase in CSF glutamate levels. Together, glutamate levels showed an insignificant trend toward increase in pups with IVH, which is consistent with the studies in rat models of hypoxia-ischemia (Vannucci et al., 1999).

\section{NBQX treatment restores myelination in rabbit pups with IVH}

Because AMPA-kainate activation mediates oligodendrocyte death and inhibits maturation of OPCs as well as myelination in models of hypoxia-ischemia (Follett et al., 2000, 2004; Volpe, 

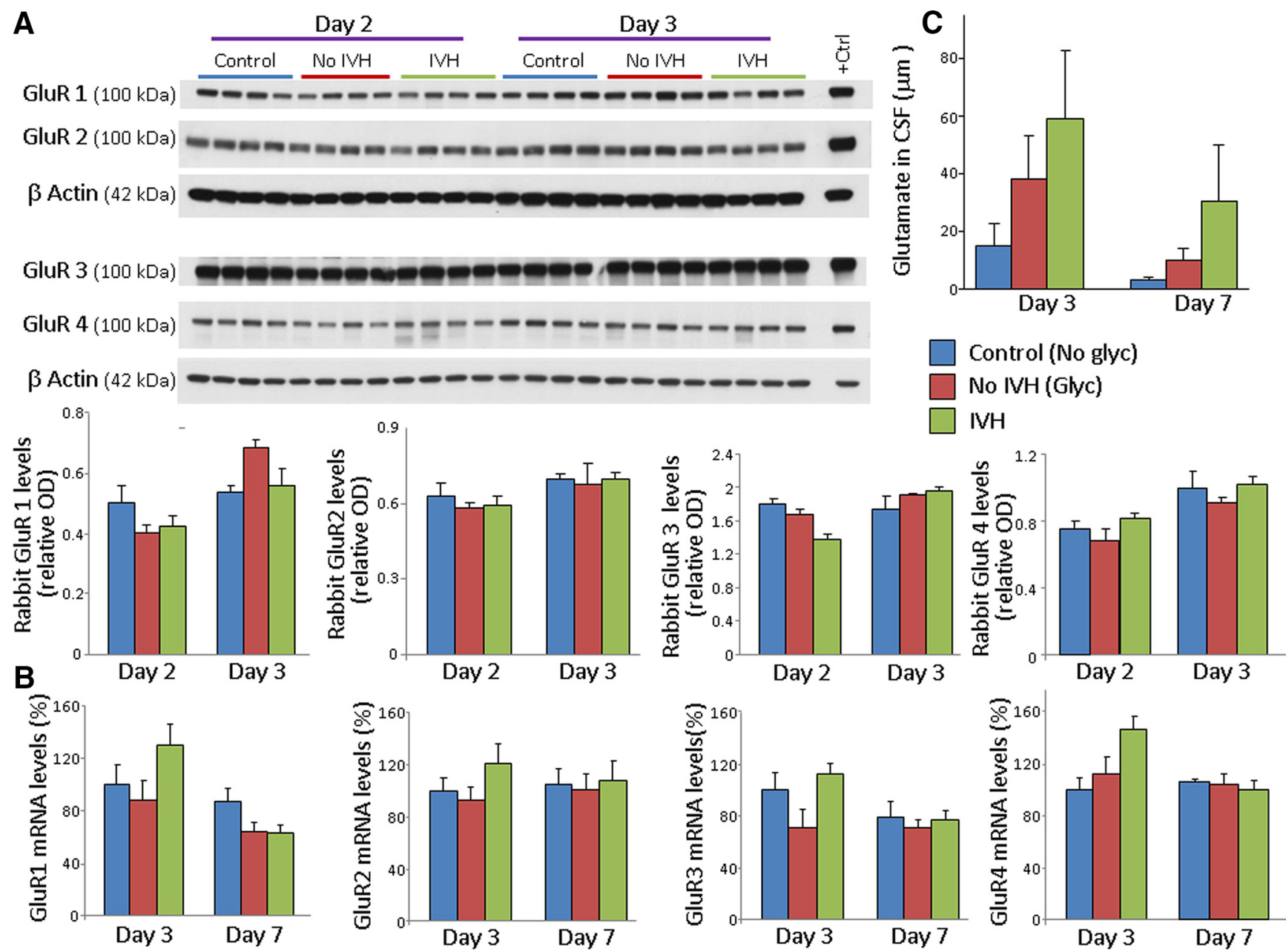

Figure 2. IVH does not affect glutamate receptor expression in preterm rabbits. $\boldsymbol{A}$, Representative Western blot analysis of the AMPA receptor subunits GluR1-GluR4 in the brain tissue from preterm rabbits with and without IVH at postnatal age 48 and $72 \mathrm{~h}$. Adult rat brain was used as positive control. Data are mean \pm SEM ( $n=5$ each). Values were normalized to $\beta$-actin. There was no significant difference in the expression of GluRs between pups with IVH and without IVH. $\boldsymbol{B}$, Data are mean \pm SEM ( $n=5$ each group). Bar charts represent mRNA expression of GluR1-GluR4 (GRIA 1-4). The mRNA expression for these receptors was comparable between pups with and without IVH at both D3 and D7. C, CSF glutamate levels show a trend toward increase in pups with IVH relative to controls; however, there was no significant difference in CSF glutamate levels between pups with and without IVH at D3 and D7. Glyc, Glycerol.

2009b), we evaluated the effect of AMPA-kainate receptor inhibition on myelination in rabbits with IVH. To this end, we compared myelination among three groups of pups at D14: (1) glycerol-treated pups without IVH, (2) vehicle-treated pups with IVH, and (3) NBQX-treated pups with IVH. To clarify, intraperitoneal glycerol was used to induce IVH, and intramuscular vehicle was administered for comparison with intramuscular NBQX. Severity of IVH was comparable between vehicle- and NBQXtreated groups, as measured by head ultrasound. Stereological quantification of MBP in immunostained sections revealed that the volume fractions (myelin load) of MBP in the corpus callosum and corona radiata were significantly less in pups with IVH relative to controls without IVH $(p<0.004)$ and that intramuscular NBQX enhanced the expression of MBP $(p=0.031$; Fig. $3 A$ ). Consistent with stereological analyses, Western blot analyses demonstrated that MBP, MAG, and CNPase levels were reduced in pups with IVH compared with controls without IVH $(p<$ $0.01, p<0.01$, and $p<0.001$, respectively) and that NBQX treatment significantly increased MBP, MAG, and CNPase expression in pups with IVH $(p=0.001, p=0.011$, and $p=0.001$, respectively; Fig. $3 B, C$ ).

Ultrastructural evaluation of the corpus callosum and corona radiata demonstrated that numbers of myelinated axons were fewer in pups with IVH compared with controls without IVH $(p<0.05$; Fig. $3 E)$ and that NBQX treatment significantly increased the density of myelinated axons in pups with IVH $(p<$ $0.05)$. Moreover, the g-ratio was comparable in the three groups of pups $(0.71 \pm 0.008$ vs $0.73 \pm 0.016$ vs $0.71 \pm 0.01$, in pups without IVH, IVH with vehicle, and NBQX treatment, respectively). This suggests that AMPA-kainate inhibition restores myelination and the morphology of the myelin sheath in the white matter of preterm rabbit pups with IVH.

\section{NBQX administration restores neurological recovery}

To determine whether NBQX treatment enhances neurological recovery of preterm rabbits with IVH, we performed neurobehavioral assessments of three sets of preterm pups at D14 (Table 2), as previously described (Vinukonda et al., 2010; Vose et al., 2013). Vehicle- and NBQX-treated groups were balanced with respect to the severity of IVH. All glycerol-treated pups without IVH were neurologically normal. In contrast, we found symmetric quadriparesis in 2 pups (18\%), asymmetric quadriparesis (left $>$ right sided weakness) in one, and left leg weakness (monoparesis) in one in the vehicle-treated group. The pups with quadriparesis were completely unable to walk, and pups with monoparesis manifested with clumsiness in the gait. Among pups 

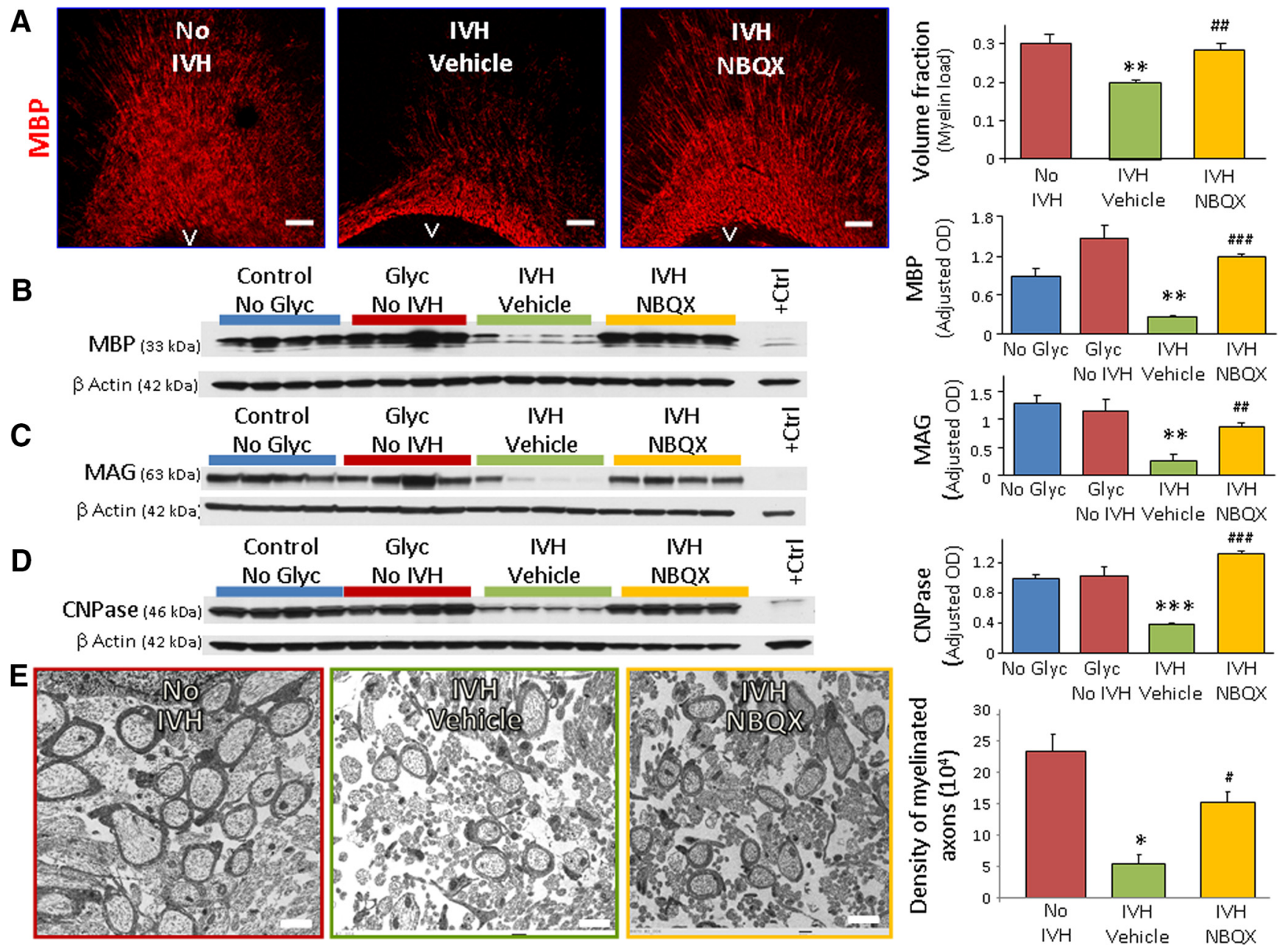

Figure 3. NBQX treatment restores myelination in rabbits with IVH. $A$, Representative immunofluorescent images of MBP in the corona radiata and corpus callosum of $D 14$ pups. Data are mean \pm SEM ( $n=8$ each group). Volume fractions of MBP were higher in the corpus callosum and corona radiata of NBQX-treated pups compared with vehicle controls with IVH. Scale bar, $200 \mu \mathrm{m}$. V, Ventricular side. B, Typical Western blots for MBP expression in the forebrain of premature rabbit pups, as indicated, at D14. Adult rat brain was used as positive control. Each lane represents lysate from a whole coronal slice taken at the level of midseptal nucleus of one brain. Bar chart represents mean \pm SEM ( $n=5$, each group). MBP expression was higher in NBQX-treated pups compared with the vehicle controls. C, Representative Western blot analysis for MAG expression in the forebrain of pups as indicated at D14. Adult rat brain was used as positive control. Bar graph represents mean \pm SEM ( $n=8$ each group). MAG expression was higher in NBQX-treated pups compared with vehicle controls. $\boldsymbol{D}$, Western blot analysis for CNPase expression in the forebrain of pups as indicated at D14. Bar graph represents mean \pm SEM ( $n=5$, each group). Similar to MBP and MAG, CNPase expression was higher in NBQX-treated pups compared with vehicle-treated controls. $\boldsymbol{E}$, Representative electron micrograph from rabbit pups with and without IVH, and pups with IVH treated with NBQX at D14. Myelinated axons were fewer in pups with IVH compared with controls without IVH, and NBQX treatment significantly increased the number of myelinated axons in pups with IVH. ${ }^{*} p<0.05,{ }^{* *} p<0.01,{ }^{* * *} p<0.001$, pups with versus without IVH. ${ }^{\#} p<0.05,{ }^{\# \#} p<$ 0.01 , vehicle versus NBQX-treated pups with IVH. ${ }^{\# \#} p<0.001$, vehicle versus NBQX-treated pups with IVH. Scale bar, $1 \mu \mathrm{m}$. Glyc, Glycerol.

treated with NBQX, one pup (10\%) showed quadriparesis and the remaining pups were neurologically normal. The scores for gait were significantly higher in NBQX-treated pups than in vehicle controls $(p<0.05)$. The average distance walked in $60 \mathrm{~s}$ was farther in NBQX-treated pups compared with vehicle controls $(p=0.04)$. The percentage of pups showing the ability to hold their position on a ramp pitched at $60^{\circ}$ inclination for $\geq 20 \mathrm{~s}$ was more in NBQX-treated pups compared with saline controls ( $90 \%$ vs $64 \%)$. Scores for the righting reflex, forearm, and hind arm movement were significantly better in NBQX-treated pups compared with vehicle controls ( $p<0.05$, for all). There was no difference in sensory and cranial nerve assessment of the three sets of rabbit pups. Importantly, we did not observe any apparent adverse effect attributable to NBQX treatment among pups with IVH receiving this medication. To test whether NBQX induces hypothermia, rectal temperature was monitored in these three sets of pups during the first $3 \mathrm{~d}$, who were reared in an infant incubator. There was no significant difference in the temperature between groups, which ranged from $36^{\circ} \mathrm{C}$ to $37^{\circ} \mathrm{C}$.

NBQX treatment reduces $\mathrm{Ca}^{+}$signaling, apoptosis, and enhances maturation of OPC

Oxygen-glucose deprivation (simulating brain ischemia) of OPCs in culture model activates $\mathrm{Ca}^{2+}$-permeable AMPA-kainate receptors (Deng et al., 2003). Because plasma has high glutamate levels and can damage OPCs due to the presence of thrombin and other components (Juliet et al., 2009), we postulated that treating OPC with plasma (simulating IVH) might enhance calcium influx in $\mathrm{O}^{+}$ OPCs. To this end, we isolated pure population of $\mathrm{O}^{+}{ }^{+}$cells from the corona radiata and corpus callosum of E29 rabbits using Magnetic Activated Cell Sorting technology. We evaluated changes in $\mathrm{Ca}^{2+}$ content using membrane-permeable $\mathrm{Ca}^{2+}$-sensitive fluorescent dye, FluoForte. Treatment of OPC with plasma significantly increased FluoForte signal intensity $(p<0.01)$, and AMPA receptor 
Table 2. Neurobehavioral evaluation of NBQX- and vehicle-treated pups with IVH and controls without IVH at the postnatal day $14^{a}$

\begin{tabular}{|c|c|c|c|c|}
\hline System & Test & $\begin{array}{l}\text { No IVH } \\
(n=11)\end{array}$ & $\begin{array}{l}\text { IVH vehicle } \\
(n=11)\end{array}$ & $\begin{array}{l}\mathrm{IVH}, \mathrm{NBQX} \\
(n=10)\end{array}$ \\
\hline \multirow{2}{*}{ Cranial nerve } & Aversive response to alcohol & $3(3,3)$ & $3(3,3)$ & $3(3,3)$ \\
\hline & Sucking and swallowing & $3(3,3)$ & $3(3,3)$ & $3(3,3)$ \\
\hline \multirow[t]{13}{*}{ Motor } & Motor activity & & & \\
\hline & Head & $3(3,3)$ & $3(3,3)$ & $3(3,3)$ \\
\hline & Fore legs & $3(3,3)$ & $3(1.25,3)^{\#}$ & $3(3,3)^{*}$ \\
\hline & Hind legs & $3(3,3)$ & $3(1,3)^{\#}$ & $3(3,3)^{*}$ \\
\hline & Righting reflex ${ }^{b}$ & $5(5,5)$ & $4(0.5,5)^{\#}$ & $5(5,5)^{*}$ \\
\hline & Locomotion on $30^{\circ}$ inclination ${ }^{c}$ & $3(3,3)$ & $3(1,3)^{\#}$ & $3(3,3)^{*}$ \\
\hline & Tone $^{d}$ : forelimb & $0(0,0)$ & $0(0,0)$ & $0(0,0)$ \\
\hline & Tone $^{d}$ : hindlimb & $0(0,0)$ & $0(0,0)$ & $0(0,0)$ \\
\hline & $\begin{array}{l}\text { Inability to hold their position } \\
\text { at } 60^{\circ}\end{array}$ & $0 \%$ & $36 \%$ & $10 \%$ \\
\hline & $\begin{array}{l}\text { Inclination for } \leq 20 \text { s (latency to } \\
\text { slip down the slope, if }<15 \text { s) }\end{array}$ & & & \\
\hline & $\begin{array}{l}\text { Inability to walk }>60 \text { inches } \\
\text { in } 1 \mathrm{~min}(\%)\end{array}$ & $0 \%$ & $36 \%$ & $10 \%$ \\
\hline & Gait $^{e}$ & $4(4,4)$ & $3(1.5,4)^{\#}$ & $4(3.5,4)^{*}$ \\
\hline & Motor impairment ${ }^{f}$ & $0 \%$ & $36 \%$ & $10 \%$ \\
\hline \multirow[t]{2}{*}{ Sensory } & Facial touch & $3(3,3)$ & $3(3,3)$ & $3(3,3)$ \\
\hline & Pain & $3(3,3)$ & $3(3,3)$ & $3(3,3)$ \\
\hline
\end{tabular}

${ }^{a}$ Values are median (interquartile range). Zero is the worst response and 3 is the best response, unless otherwise noted.

${ }^{b}$ Score (range, 1-5): no. of times turns prone within $2 \mathrm{~s}$ when placed in supine out of 5 tries.

'Score (range, $0-3$ ): 0 , does not walk; 1 , takes a few steps ( $<8$ inches); 2 , walks for $9-18$ inches; 3 , walks very well beyond 18 inches.

${ }^{d}$ Score (range, 1-3): 0 , no increase in tone; 1 , slight increase in tone; 2 , considerable increase in tone; 3 , limb rigid in flexion or extension.

${ }^{e} G$ ait was graded as follows: 0 , no locomotion; 1 , crawls with trunk touching the ground for few steps and then rolls over; 2, walks taking alternate steps, trunk low, and cannot walk on inclined surface; 3 , walks taking alternate steps, cannot propel its body using synchronously the hind legs, but walks on $30^{\circ}$ inclined surface; 4 , walks, runs, and jumps without restriction, propels the body using synchronously the back legs, but limitation in speed, balance, and coordination manifesting as clumsiness in gait; 5 , normal walking.

${ }^{f}$ Motor impairment was defined as weakness in either fore legs or hind legs and distance walked $<60$ inches in $60 \mathrm{~s}$. ${ }^{*} p<0.05$, for vehicle-treated versus NBQX-treated pups with IVH.

$\# p<0.05$, for glycerol-treated pups without IVH and vehicle-treated pups with IVH.

inhibition by NBQX treatment reduced the fluorescence intensity in the OPCs ( $p<0.05$; Fig. $4 A$ ). This could be a mechanism by which IVH may increase $\mathrm{Ca}^{2+}$ influx into the OPCs to damage these cells in our rabbit model.

We next asked whether NBQX treatment reduced apoptosis of OPCs in rabbits with IVH. To this end, we double-labeled brain sections for TUNEL and O4 antigen. We found that apoptotic $\mathrm{O}^{+}{ }^{+}$cells were significantly more abundant in the corpus callosum and corona radiata of pups with IVH compared with glycerol-treated controls without IVH at D3 $(p<0.01)$ and that NBQX treatment substantially reduced the density of apoptotic $\mathrm{O}^{+}$cells $(p=0.004$; Fig. $4 B)$.

Because NBQX enhanced myelination in our glycerol model of IVH, we postulated that NBQX treatment might affect proliferation and maturation of OPCs. To assess proliferation of OPC in the corona radiata and corpus callosum, we compared cycling and total PDGFR $\alpha^{+}$progenitor cell in glycerol-treated pups without IVH, vehicle-treated, and NBQX-treated pups with IVH. The densities of both total and cycling PDGFR $\alpha^{+}$cells showed a trend toward reduction in pups with IVH compared with controls without IVH. However, the comparisons between the three groups were not statistically significant (Fig. 4C).

We next evaluated the effect of NBQX treatment on OPC maturation in sections double-labeled with Olig2- and Nkx2.2-specific antibodies. We found that Olig2 ${ }^{+}$OPCs were comparable between the three groups. However, the population of Olig ${ }^{+} \mathrm{Nkx} 2.2^{+}$cells was significantly reduced in pups with IVH relative to controls without IVH ( $p=0.006)$, and NBQX treatment significantly increased their density $(p=0.04)$ in the corona radiata and corpus callosum (Fig. 4D). This suggests that NBQX treatment restores the maturation of OPCs in pups with IVH. Consistent with this conclusion, we found higher levels of CNPase $\left(2^{\prime}, 3^{\prime}\right.$-cyclic nucleotide- $3^{\prime}$ phosphodiesterase), as measured by Western blot analyses, in NBQX-treated pups with IVH compared with vehicle controls (Fig. $3 D$ ) at D14. Together, NBQX treatment favors maturation of OPCs but does not affect its proliferation.

\section{NBQX suppresses microglia infiltration and proinflammatory cytokines}

As glutamate excitotoxicity might activate microglia and cerebral inflammation (Volpe, 2009b; Kostic et al., 2013), we asked whether IVH-induced cerebral inflammation and production of inflammatory mediators, and whether this can be alleviated by NBQX treatment. To this end, we quantified $\mathrm{Ibal}^{+}{ }^{+}$microglia in immunolabeled sections and assayed mRNA expression of proinflammatory cytokines, including TNF $\alpha, I L 1 \beta, I L-6, L I F, C N T F$, and interferon- $\gamma$, by qRT-PCR using TaqMAN probes (Fig. 5).

We found that the development of IVH significantly increased the density of $\mathrm{Ibal}^{+}$microglia in both periventricular ganglionic eminence and corona radiata $(p=0.001$ and $p=0.004$, respectively) and, more importantly, NBQX treatment restored their density ( $p=0.001, p<0.05$; Fig. $5 A, B$ ). Consistent with these findings, the onset of IVH led to an elevation in the expression of $T N F \alpha, I L 1 \beta, I L-6$, and LIF mRNA $(p=0.004, p=0.001, p=$ 0.001 , and $p=0.001$, respectively) and NBQX treatment reduced their levels $(p=0.005, p=0.035, p=0.001$, and $p=0.013$, respectively; Fig. 5C). However, the levels of interferon- $\gamma$ and $\mathrm{CNTF}$ were neither elevated in pups with IVH nor reduced with NBQX treatment. This suggests that IVH-induced inflammation is significantly curtailed by NBQX treatment.

\section{NBQX treatment does not affect astrogliosis}

Because AMPA receptor inhibition alleviates $\mathrm{Ca}^{2+}$-mediated excitotoxicity and cell death (Fern and Möller, 2000; Follett et al., 2004), we reasoned that NBQX treatment might reduce astrogliosis. Hence, we used stereological evaluation of immunostained sections and Western blot analyses to compare GFAP expression between control pups without IVH (glycerol treated), vehicle- and NBQX-treated pups with IVH. We found that GFAP expression was elevated in pups with IVH compared with controls without IVH at D14 ( $p=$ 0.013 and $p=0.001$ in stereology and Western blot analyses, respectively; Fig. $6 A-C)$. However, there was no difference in the GFAP expression between vehicle- and NBQX-treated pups with IVH. GFAP expression was also elevated at D3 in pups with IVH compared with controls without IVH $(p<0.01)$.

Because NBQX treatment promotes myelination in pups with IVH, we reasoned that this might influence myelination or gliosis in healthy pups. Hence, we compared MBP and GFAP levels in the vehicle- and NBQX-treated healthy pups at D14 (data not shown). We found that NBQX treatment did not significantly affect myelination or astrogliosis in healthy pups without IVH.

\section{NBQX blocks p-STAT3 signaling but does not affect astrocyte proliferation}

STAT-3 is a member of JAK-STAT signaling family, which triggers responses of several cytokines and growth factors (Aaronson and Horvath, 2002). Elevation in both total and p-STAT3 indicates activation of STAT-3 signaling (Sehgal, 2008). Because ele- 


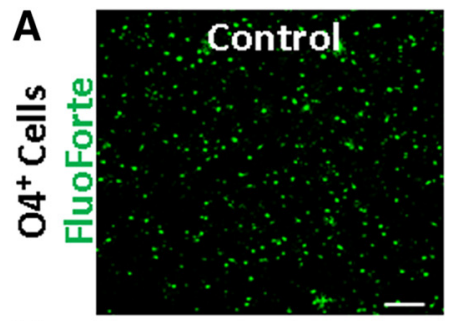

B

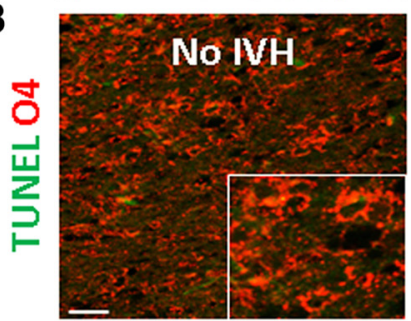

C
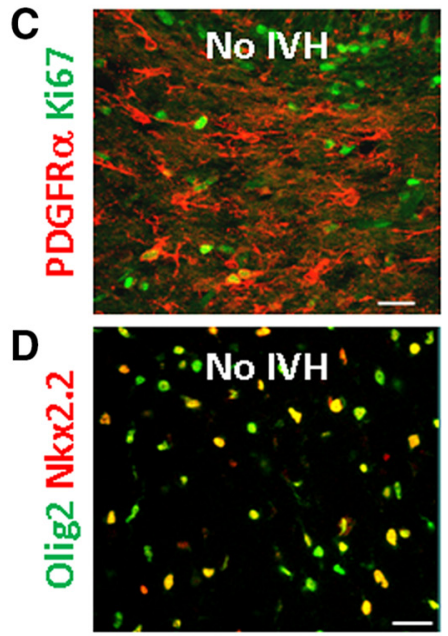
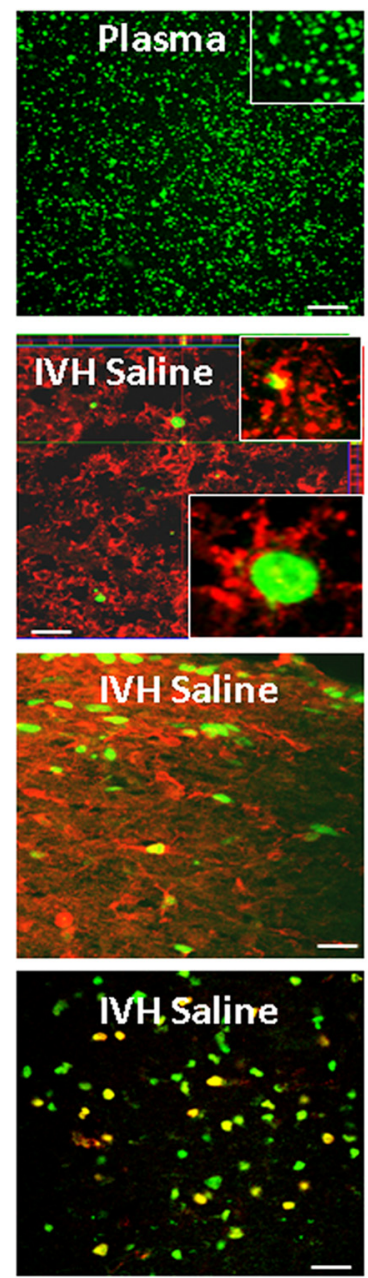
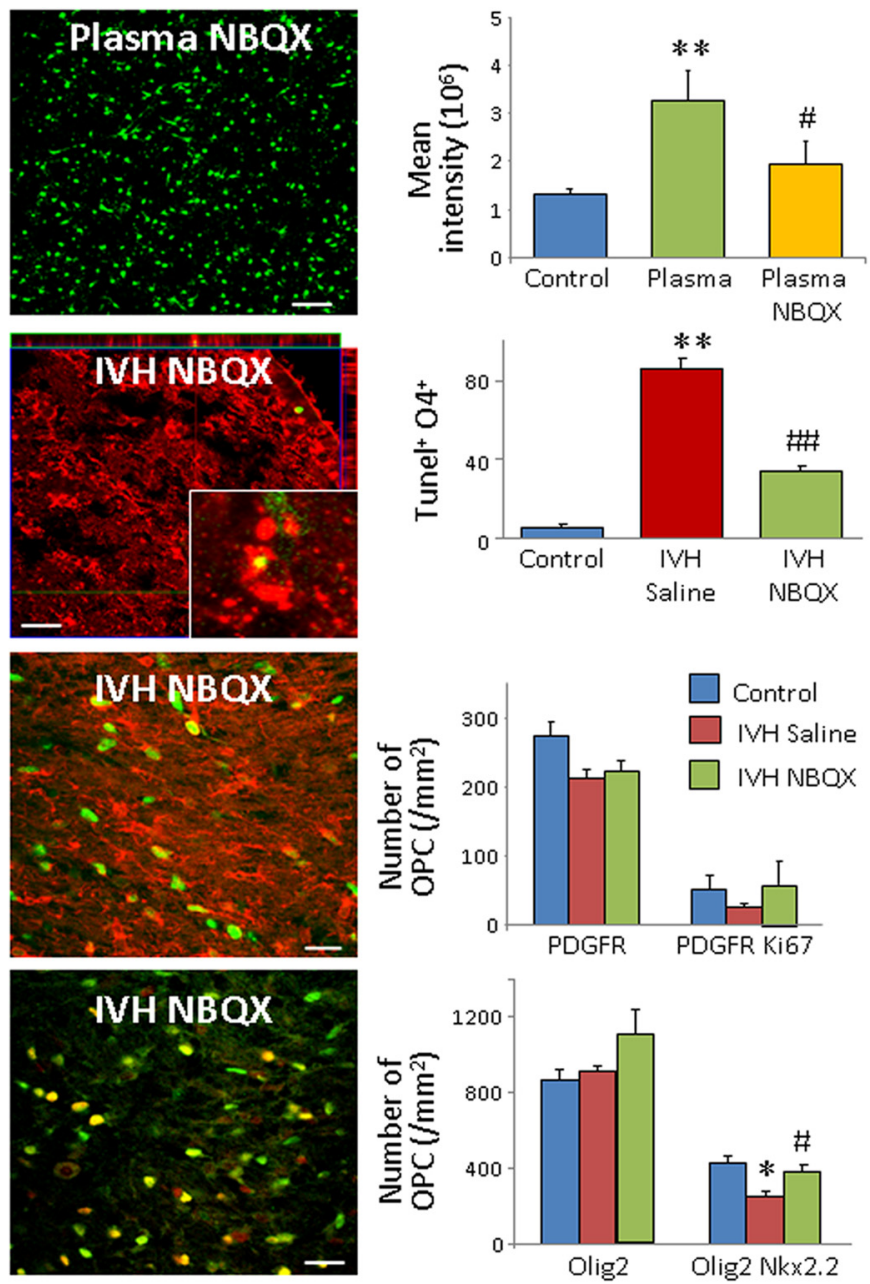

Figure 4. NBQX treatment reduces $\mathrm{Ca}^{2+}$ influx in $04^{+}$cells treated with plasma and minimizes apoptosis and promotes maturation of OPC in rabbits with IVH. $\boldsymbol{A}$, Representative image of the Fluo-Forte-labeled $\mathrm{O4}^{+}$cells exposed to plasma or plasma with NBQX. Quantification of mean fluorescence intensities is represented as mean \pm SEM $(n=5)$. $\boldsymbol{B}$, Representative images of TUNEL (green) and 04 immunostaining for OPCS (red) in the corona radiata, as indicated. Insets, High-magnification views. TUNEL ${ }^{+} \mathrm{OPCS}$ were reduced in NBQX-treated pups with IVH compared with vehicle controls. C, A typical image of cryosections (D3 pup) double-labeled with PDGFR $\alpha$ - and Ki67-specific antibodies. Graphs represent mean \pm SEM ( $n=5$ each). Total (both cycle and noncycling) PDGFR $\alpha^{+}$cells are comparable in the three groups, as indicated. Cycling PDGFR $\alpha^{+}$cells are reduced in pups with IVH, and NBQX treatment shows an insignificant trend toward increase in the density of these cells compared with vehicle controls. D, Representative images of cryosections of D7 pup double-labeled with Olig2-and Nkx2.2-specific antibodies. Quantification represents mean \pm SEM $\left(n=5\right.$ each). Note an increase in Nkx2.2 ${ }^{+}$Olig2 ${ }^{+}$cells in NBQX-treated pups relative to vehicle controls. ${ }^{*} p<0.05$, pups with versus without IVH. ${ }^{* *} p<0.001$, pups with versus without IVH. ${ }^{\#} p<0.05$, vehicle versus NBQX-treated pups with IVH. ${ }^{\# \#} p<0.001$, vehicle versus NBQX-treated pups with IVH. Scale bar, $50 \mu \mathrm{m}$.

vated levels of several proinflammatory cytokines in pups with IVH were substantially reduced by NBQX treatment, we postulated that the IVH might induce STAT3 phosphorylation and that NBQX treatment could suppress the STAT3 activation. To this end, we compared levels of STAT and p-STAT (tyrosine 705 and serine 707) in control pups without IVH, vehicle-, and NBQX-treated pups with IVH at D3. We found that IVH enhanced total STAT $(p<0.05)$ and phosphorylation of tyrosine residues in STAT3 species $(p<0.001)$, but not of serine. More importantly, NBQX treatment reduced phosphorylation of tyrosine (tyrosine 705) in STAT3 protein in pups with IVH $(p<$ 0.001; Fig. 7A). Elevation in both total and p-STAT3 indicates their activation (Sehgal, 2008). To determine the specific neural cell type undergoing STAT-3 phosphorylation, we doublelabeled the brain sections with p-STAT3 and Olig2, GFAP, or Sox 2 antibodies. We found that $\mathrm{p}$-STAT- $3^{+}$cells were more abundant in rabbits with IVH compared with controls without IVH and NBQX-treated pups (Fig. 7B). Importantly, p-STAT-3 was abundantly expressed on Sox $2^{+}$cells of the ventricular zone and subventricular zone and also on several Olig- $2^{+}, \mathrm{GFAP}^{+}$, and $\mathrm{S} 100 \beta^{+}$cells of the periventricular white matter of pups with IVH (Fig. 7B). This suggests that STAT-3 phosphorylation involves Sox $2^{+}$progenitors and also cells of both astrocytic and oligodendroglial lineage.

JAK-STAT pathway is activated in brain disorders, including ischemia, degeneration, and cancer, and regulates expression of genes related to cell survival, proliferation, and differentiation (Cattaneo et al., 1999). STAT signaling also plays key role in astrogliosis (Herrmann et al., 2008). Because IVH increased GFAP expression and as NBQX inhibited STAT3 activation, we postulated that NBQX treatment might attenuate astrocyte proliferation and affect transcription factor regulating astrocytes, including NFIA and Sox9. To this end, we (1) evaluated astrocyte proliferation by double immunolabeling section with $S-100 \beta$ and ki67 antibodies and (2) quantified expression of NFIA and Sox9 transcription factor at D3. We found that NBQX treatment neither affected proliferation of S100 $\beta^{+}$astrocytes (data not shown) nor significantly influenced protein or mRNA expression of NFIA and Sox9 expression (Fig. 7B; qRT-PCR data not shown). Moreover, NICD protein and Hes1 mRNA expression were not 
A

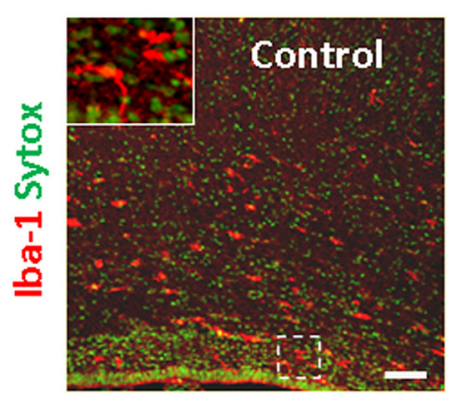

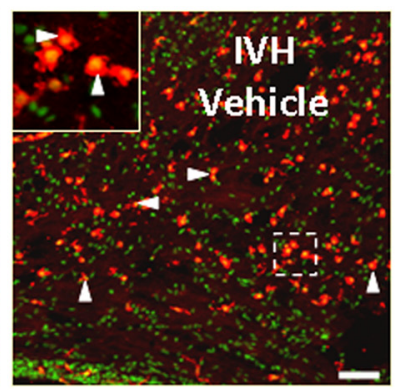

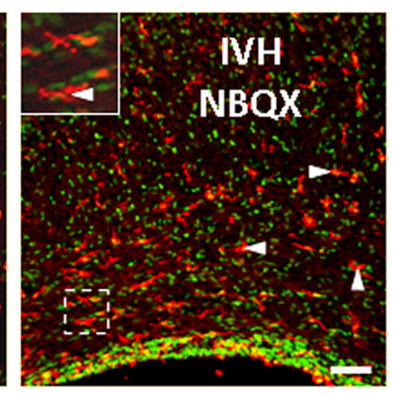

B

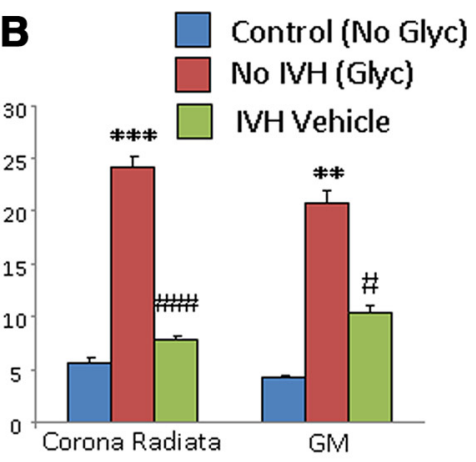

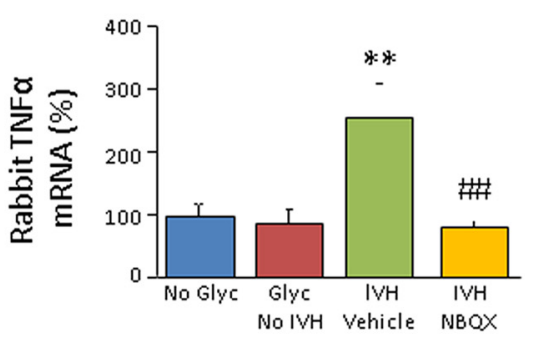

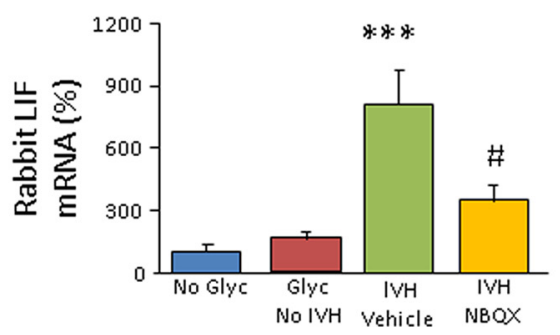

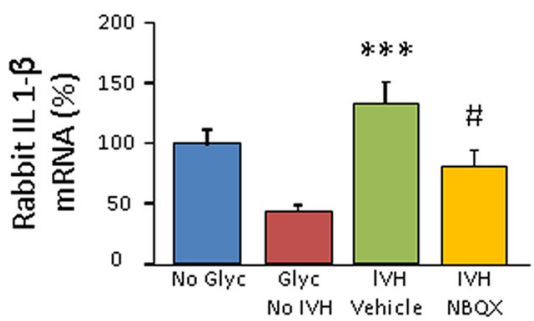

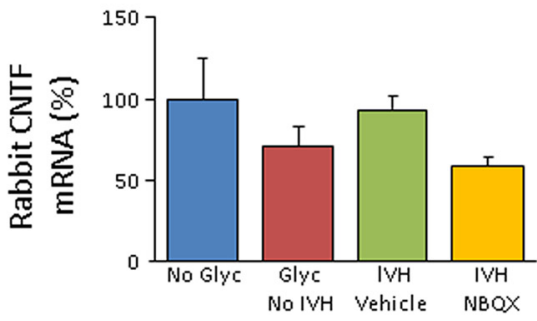

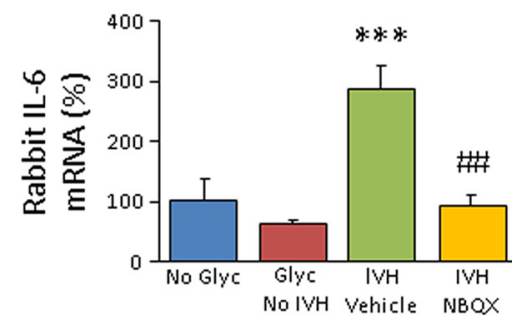

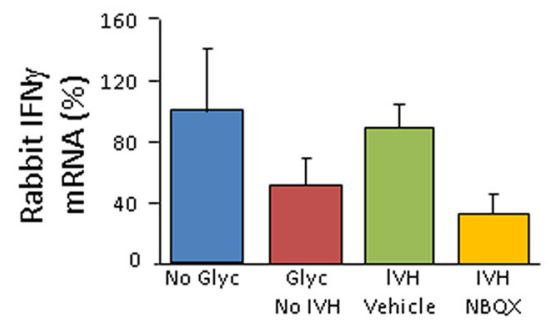

Figure 5. NBQX suppresses microglia infiltration and production of proinflammatory cytokines. $\boldsymbol{A}$, Representative images of cryosections form the corona radiata stained with Iba-1-specific antibody and sytox (nuclear stain) of D3 pups. Insets, High-magnification views of the boxed area in the image. Iba- $1^{+}$microglia (arrow) are more abundant in pups with IVH relative to controls without IVH, and NBQX treatment reduces their density. Scale bar, $50 \mu \mathrm{m}$. B , Data are mean \pm SEM ( $n=5$ each group), showing data from corona radiata and germinal matrix (GM). $\boldsymbol{C}$, TNF $\alpha, I L 1 \beta$, IL-6, and LIF mRNA levels were elevated in pups with IVH compared with controls without IVH at D3, and NBQX treatment reduced these levels in pups with IVH. Interferon (IFN) $\gamma$ and CNTF gene expression was similar between groups. Data are mean $\pm \mathrm{SEM}\left(n=5\right.$ each group). ${ }^{*} p<0.05$, pups with versus without IVH. ${ }^{* *} p<0.01$, pups with versus without IVH. ${ }^{* *} p<0.001$, pups with

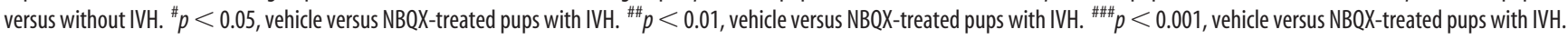

substantially affected by the development of IVH and subsequent NBQX treatment (Fig. 7B; data not shown), indicating a lack of effect of NBQX on Notch signaling pathways. Together, IVH activates STAT-3 phosphorylation, which is abrogated by NBQX treatment. A failure of NBQX treatment to affect astrocyte proliferation and astrogliosis suggests that pathways other than STAT-3 activation, such as bone morphogenetic protein and transforming growth factor $\beta$, might be playing an important role in the IVH-induced gliosis.

\section{Effect of FDA-approved perampanel on myelination, gliosis,} and neurobehavior

NBQX is known to offer neuroprotection in numerous animal models of brain injury (Pulsinelli et al., 1982; Choi, 1995; Goda et al., 2002; Groom et al., 2003), but it has not been approved for clinical use in patients because of its adverse effects. By contrast, perampanel is a noncompetitive inhibitor of AMPA receptors and has been approved by FDA for use as an antiepileptic in patients with partial-onset seizures. Because perampanel is a safe and specific AMPA inhibitor and can potentially be used in infants with IVH, we evaluated the effect of intramuscular perampanel treatment in pups with IVH starting at D1. To this end, we compared myelination and astrogliosis in pups without IVH, perampanel-treated pups with IVH, and vehicle controls. Stereological quantification of MBP in immunolabeled sections revealed that the volume fractions of $\mathrm{MBP}$ in the corpus callosum and corona radiata were significantly higher in perampaneltreated pups with IVH compared with vehicle controls ( $p=$ 0.004; Fig. 8A). Accordingly, Western blot analyses demonstrated that MBP and MAG levels were reduced in pups with IVH relative to controls without IVH ( $p<0.001$ each) and that perampanel treatment significantly increased MBP and MAG levels in pups with IVH ( $p=0.001$ each; Fig. $8 B, C)$.

We next evaluated GFAP expression in the above sets of pups. We found that GFAP expression was higher in IVH pups relative to controls without IVH both on stereological quantification of immunostained sections and Western blot analyses $(p=0.006$ and $p=$ 0.01 , respectively), and perampanel treatment did not affect the GFAP expression in pups with IVH. Likewise, the development of IVH elevated vimentin expression on Western blot analyses $(p<$ 0.001 ), and perampanel treatment did not affect its levels.

We next compared neurobehavioral performance of perampanel- and saline-treated pups with IVH ( $n=8$ each). The two groups were comparable with respect to the severity of IVH. All glycerol-treated pups without IVH were neurologically normal. In contrast, we found symmetric quadriparesis in one pup 

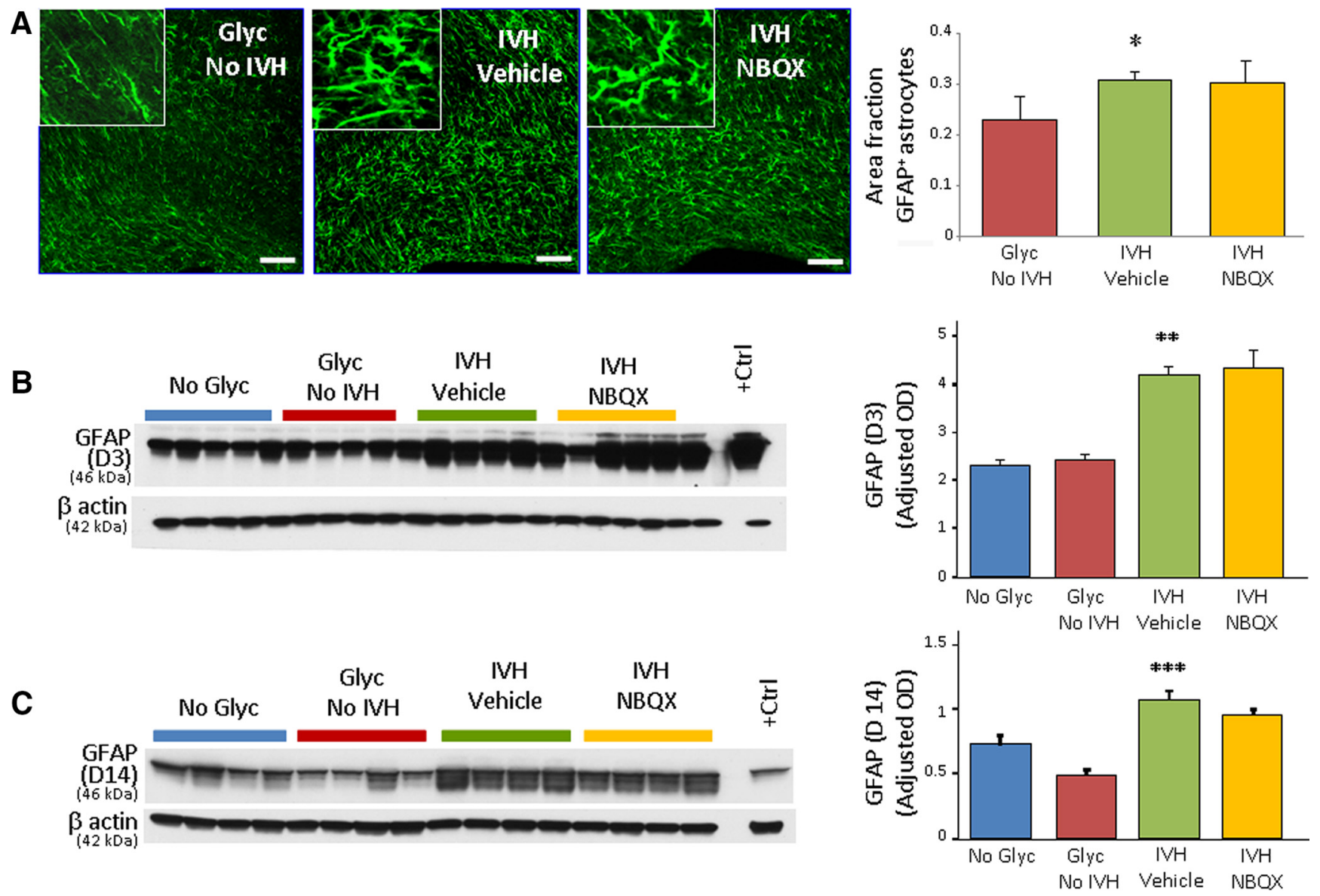

Figure 6. NBQX treatment does not alter GFAP expression. $A$, Representative immunofluorescence of GFAP in the cryosections from D14 pups, as indicated. Abundant hypertrophic astrocytes were observed in vehicle- and NBQX-treated pups with IVH. Scale bar, $50 \mu \mathrm{m}$. Inset, High-power view of astrocytes. Data are mean \pm SEM ( $n=5$ each). NBQX treatment did not affect volume fraction of astroglial fibers compared with vehicle controls on stereological analyses on D14. B, Western blot analyses for GFAP were performed in forebrain homogenates of pups at D3. Adult rat brain was positive control. Data are mean \pm SEM $(n=5$ each). Values were normalized to $\beta$-actin. IVH increased GFAP levels, and NBQX treatment did not affect GFAP expression in pups with IVH. $C$, Western blot analyses for GFAP were performed in forebrain homogenates of pups (D14). Adult rat brain was positive control. Data are mean \pm SEM ( $n=5$ each). Values were normalized to $\beta$-actin. IVH increased GFAP levels, and NBQX treatment did not affect GFAP expression in pups with IVH. ${ }^{*} p<0.05$, no IVH versus IVH. ${ }^{* *} p<0.01$, no IVH versus IVH. ${ }^{* * *} p<0.001$, no IVH versus IVH.

(12.5\%), and left/right leg weakness (monoparesis, 25\%) in two saline-treated pups. The pup with quadriparesis was completely unable to walk, and pups with monoparesis manifested with clumsy gait. All perampanel-treated pups were neurologically normal. The scores for gait were significantly higher in perampanel-treated pups compared with saline controls $(p<$ $0.05)$. The percentage of pups showing inability to hold their position on a ramp pitched at $60^{\circ}$ inclination for $\geq 20 \mathrm{~s}$ was significantly higher in NBQX-treated pups compared with the saline controls. Scores for the righting reflex and hind arm movement were superior in perampanel-treated pups compared with saline controls ( $p<0.05$, all). There was no significant difference in sensory and cranial nerve assessment of the three sets of rabbit pups. Importantly, we did not observe any apparent adverse effect attributable to perampanel treatment among pups with IVH. There was also no significant difference in the temperature between groups, similar to NBQX-treated pups.

\section{Discussion}

IVH occurs in $\sim 12,000$ premature infants every year in the United States. Because survival rates of premature infants have strikingly improved, neurologic sequelae of IVH have emerged as important public health concerns. Yet, no effective therapy exists to prevent the white matter injury in the survivors of IVH. In the present study, we found that AMPA-kainate receptor inhibition alleviated IVH-induced inflammation, reduced calcium signaling in OPCs, restored maturation of OPCs, and promoted myelination and neurologic recovery in preterm rabbits with IVH. Similar restoration of myelination and neurological function were observed with the AMPA-kainate antagonist NBQX and the FDA-approved AMPA-specific inhibitor perampanel. Hence, the present study highlights the role of AMPA-kainate receptor in IVH-induced white matter injury and identifies a novel strategy of neuroprotection in premature newborns with IVH.

The most important and novel observation in this study was that AMPA-kainate receptor inhibition reduced apoptosis of OPCs, enhanced OPC maturation, and promoted myelination in a rabbit model of IVH. To our knowledge, this is the first demonstration that AMPA-kainate inhibition protects OPCs and improves myelination in an animal model of IVH. However, a number of studies have examined the neuroprotective role of AMPA-kainate antagonists in animal models of neonatal hypoxia-ischemia, perinatal inflammation, and multiple sclerosis (Fern and Möller, 2000; Follett et al., 2000, 2004; Deng et al., 2003; Kanwar et al., 2004). Consistent with our study, treatment with NBQX and the anticonvulsant topiramate reduces oligodendrocyte death and enhances myelination in rodent model of 

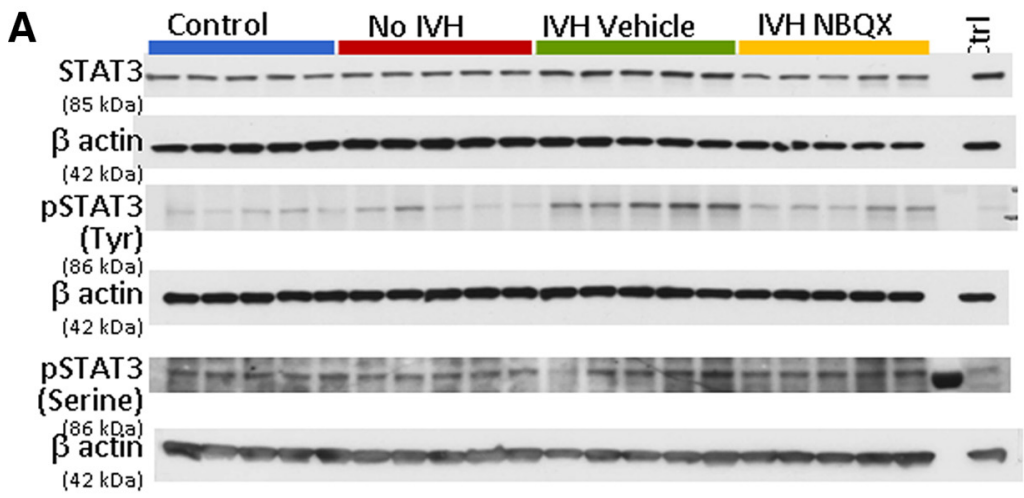

B
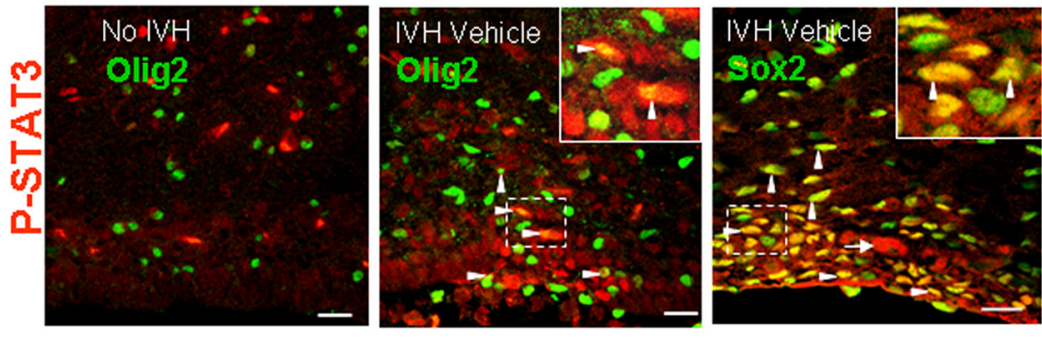

C

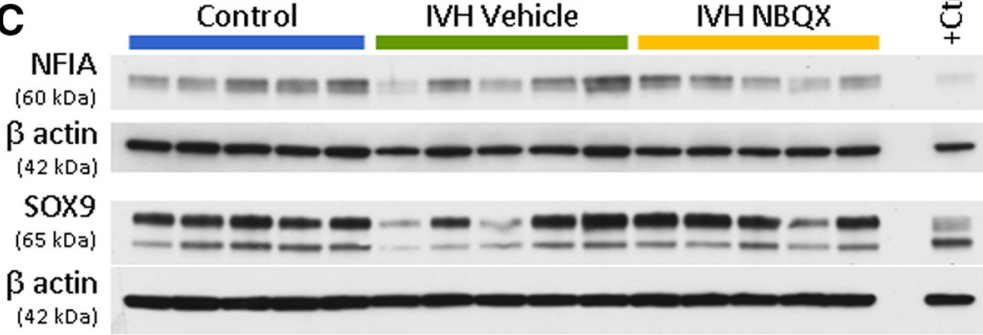

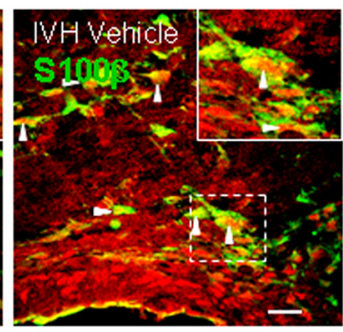
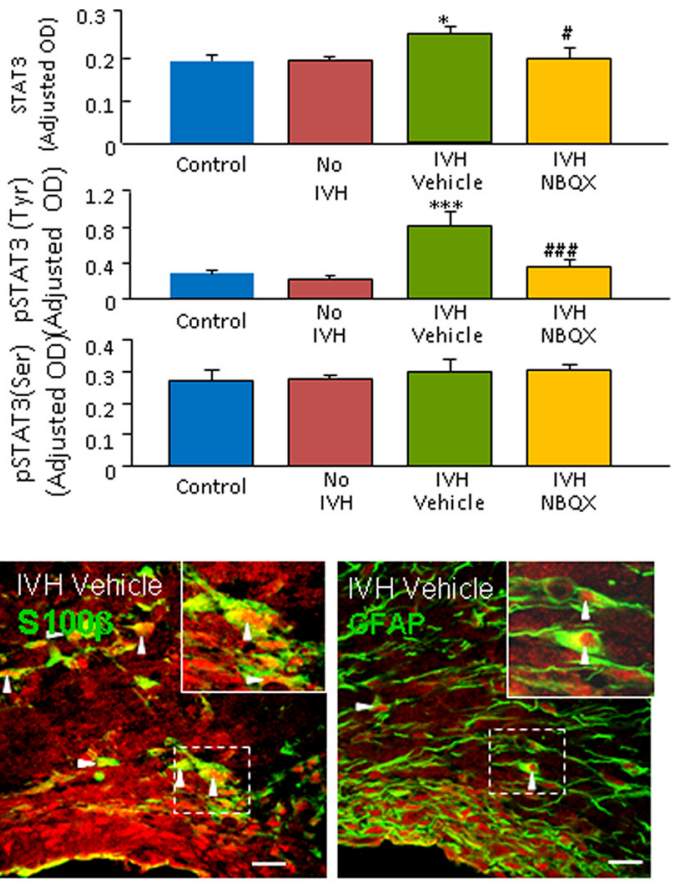

品 0

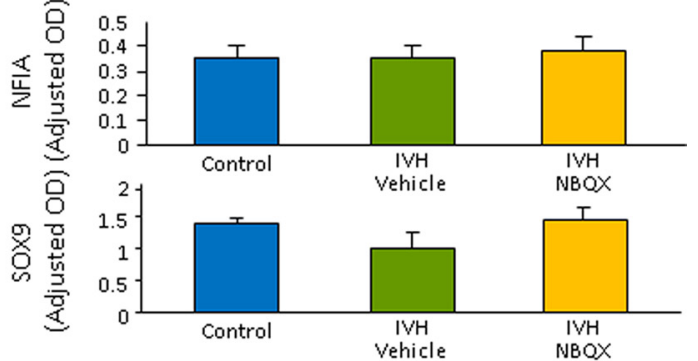

Figure 7. NBQX blocks p-STAT3 signaling. $\boldsymbol{A}$, Representative Western blot analysis for total STAT3, pSTAT3 (Tyr), and pSTAT3 (Ser) levels in the brain homogenates from preterm rabbits as indicated. Adult rat brain was positive control. Values were normalized to $\beta$-actin. Data are mean \pm SEM ( $n=5$ each). Total STAT- 3 and pSTAT(Tyr) levels were significantly increased in pups with IVH compared with pups without IVH, which were significantly reduced by NBQX treatment. However, pSTAT3 (Ser) expression was comparable between groups. $\boldsymbol{B}$, Representative immunofluorescence of cryosections from 3-d-old E29 pup double-labeled with p-STAT-3 and 0lig2-, GFAP-, or Sox2-specific antibodies. p-STAT-3 was expressed more abundantly in IVH pups compared with controls without IVH. Also, Sox2 ${ }^{+}, 0$ lig- $2^{+}, \mathrm{GFAP}^{+}$, and S100 $\beta^{+}$cells (arrowhead) coexpress p-STAT3 in the periventricular white matter. Inset, High-power view of the boxed area in the image. Scale bar, $20 \mu \mathrm{m}$. C, Representative Western blot analysis for nuclear factor $1 \mathrm{~A}$ (NFIA), Sox9, and NICD expression in the brain homogenates from preterm rabbits, as indicated. Values were normalized to $\beta$-actin. Data are mean \pm SEM ( $n=5$ each). NFIA, Sox9, and NICD levels were comparable between groups, as indicated.

neonatal hypoxia-ischemia (Follett et al., 2004). NBQX improves survival of OPCs and remyelination as well as reduces axonal damage resulting in amelioration of disease process in animals models of multiple sclerosis (Groom et al., 2003; Kanwar et al., 2004). However, systemic NBQX treatment has failed to reduce apoptosis of OPCs in a neonatal model of the IL- $6 \beta$-induced white matter injury (Cai et al., 2004). The role of AMPA-kainate receptors has also been previously evaluated in oligodendrocyte culture experiments. Primary OPC cultures under the conditions of oxygen-glucose deprivation have shown activation of $\mathrm{Ca}^{2+}$ permeable AMPA receptors and NBQX treatment has offered cytoprotection, suggesting AMPA-kainate receptors to be a major mechanism of OPC injury (Follett et al., 2000; Tekkök and Goldberg, 2001; Deng et al., 2003). Among cells of oligodendrocyte lineage, mature oligodendrocytes are less vulnerable to injury compared with immature OPCs and preoligodendrocytes (Fern and Möller, 2000; Follett et al., 2000). Together, AMPAkainate inhibition might offer an important strategy of neuroprotection in premature infants with IVH.

Although we observed neuroprotection with NBQX treatment, this agent exhibits renal toxicity and is not in clinical use.
Therefore, we tested perampanel, an FDA-approved antiepileptic drug, in our model, which showed similar effects in enhancing myelination and neurological recovery as NBQX treatment. Perampanel is a potent, noncompetitive, and selective AMPA receptor antagonist and a broad-spectrum anticonvulsant (Hanada et al., 2011). It has low side-effect profile and lacks psychomimetic properties because it does not interact with NMDA receptors (Rogawski, 2011). Moreover, it has an attractive pharmacokinetic profile. For example, it has a long half-life, allowing oncedaily dosing, and interaction to other antiepileptic drugs is limited to oxycarbazepine (Hanada et al., 2014). Dizziness and somnolence are the common adverse effects in adult patients. Perampanel has shown efficacy and safety in Phase III clinical trials for partial seizures in a dose of 8 and $12 \mathrm{mg}$ (Gidal et al., 2015; Vazquez et al., 2015). In the present study, we treated rabbits with perampanel at $18-20 \mathrm{~h}$ after the induction of IVH. Because $90 \%$ of all IVH occur within $72 \mathrm{~h}$ of birth and as preterm infants in neonatal units undergo screening head ultrasound to detect IVH during this period, it is feasible to initiate perampanel treatment on these infants shortly after the development of IVH. 

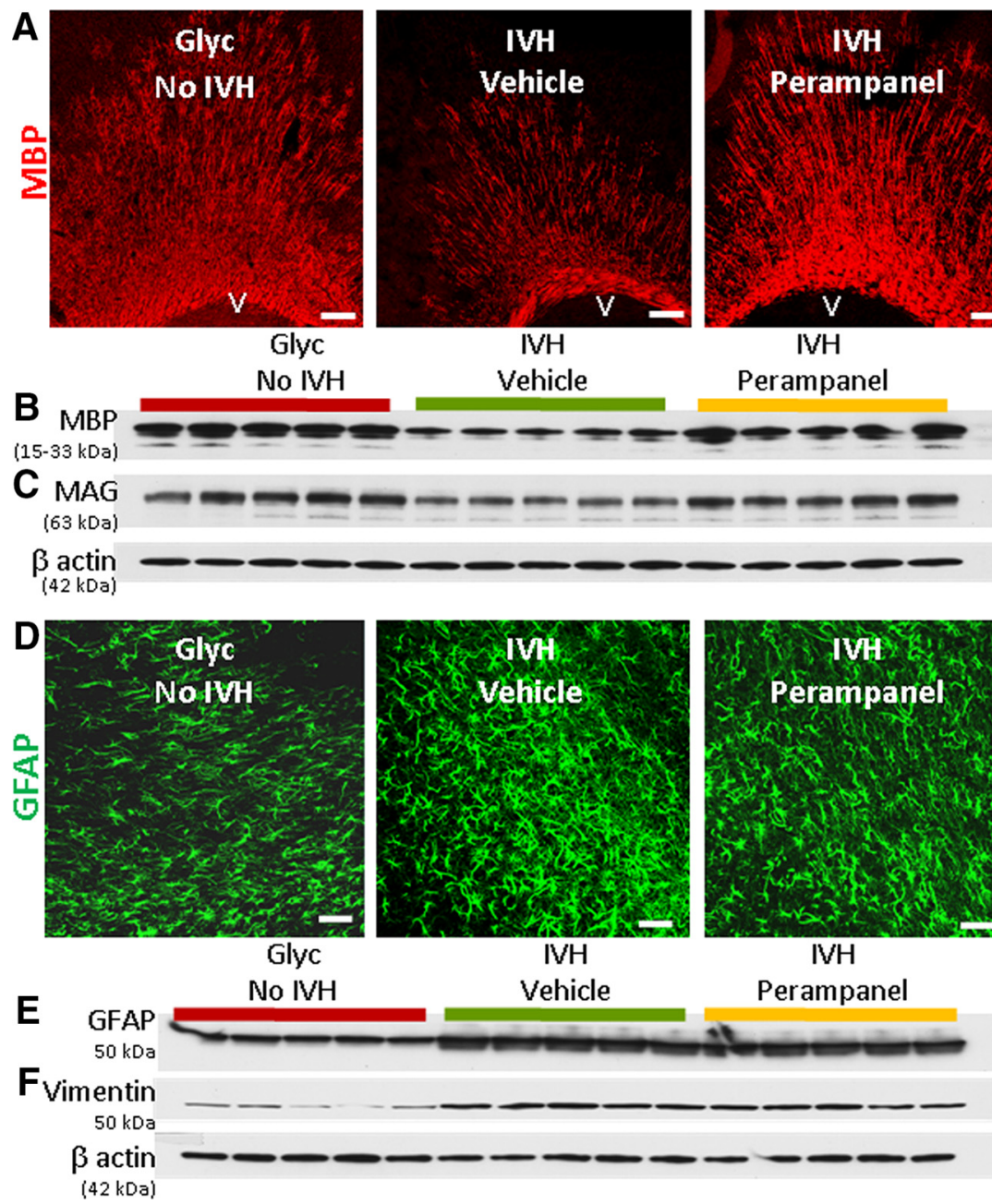

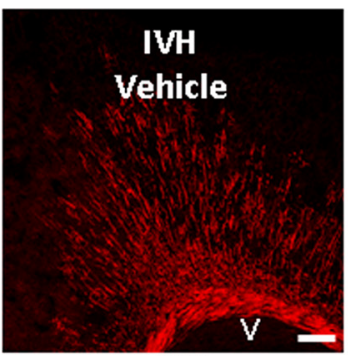

IVH Vehicle
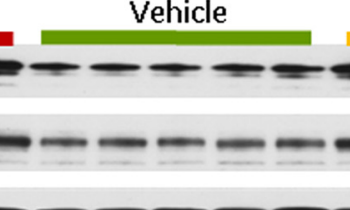

$-1$

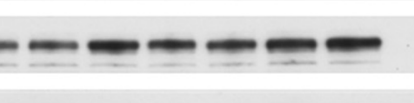

$\mathrm{VH}$

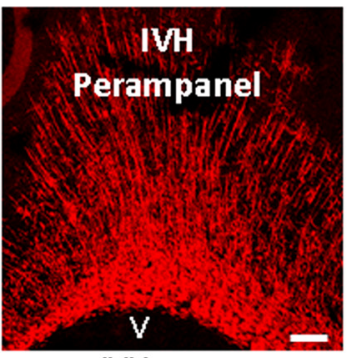

Perampanel

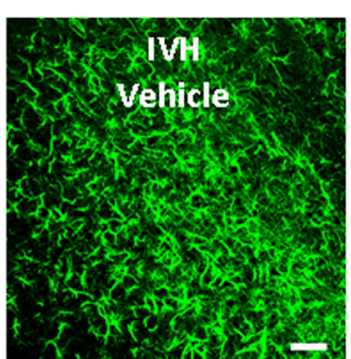

IVH
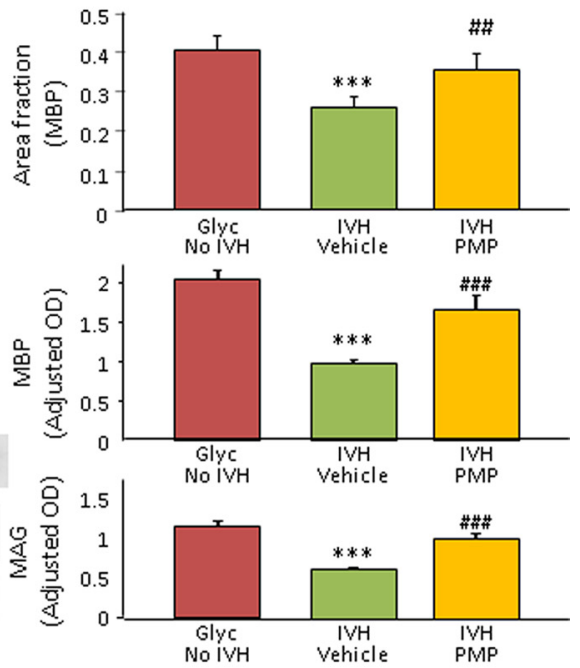
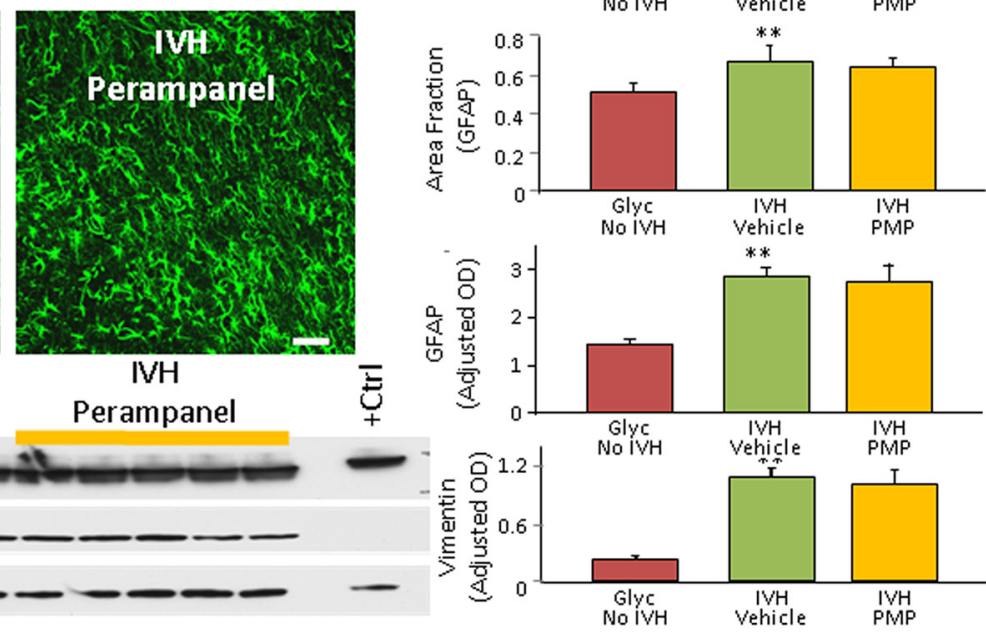

Figure 8. Perampanel treatment restores myelination in rabbits with IVH. $\boldsymbol{A}$, Representative immunofluorescence of MBP in the corona radiata of D14 pups. Data are mean \pm SEM ( $n=5$ each group). Volume fractions of MBP were higher in the corpus callosum and corona radiata of perampanel-treated pups compared with vehicle controls with IVH. Scale bar, $200 \mu \mathrm{m}$. V, Ventricular side. $\boldsymbol{B}$, Typical Western blot analysis for MBP expression in the forebrain of premature rabbit pups, as indicated, at D14. Adult rat brain was used as positive control. Each lane represents one brain. Bar chart represents mean \pm SEM ( $n=5$ each group). MBP abundance was higher in perampanel-treated pups compared with vehicle controls. $C$, Western blot analysis of MAG expression in the forebrain of pups as indicated at D14. Bar graph represents mean $\pm \operatorname{SEM~(~} n=5$ each group). MAG expression was higher in perampanel-treated pups compared with vehicle controls. ${ }^{* * *} p<0.001$, pups with versus without IVH. ${ }^{\#} p<0.05$, vehicle versus parempanel-treated pups with IVH. ${ }^{\# \#} p<0.001$, vehicle versus parempanel-treated pups with IVH. $\boldsymbol{D}$, Representative immunofluorescence of corona radiata from cryosections labeled with GFAP antibody, as indicated. Note abundant hypertrophic astrocytes in vehicle- and NBQX-treated pups with IVH. Scale bar, $50 \mu \mathrm{m}$. Data are mean \pm SEM ( $n=5$ each). Perampanel treatment did not affect volume fraction of astroglial fibers compared with vehicle controls on stereological analyses. $E, F$, Western blot analyses for GFAP and vimentin were performed in forebrain homogenates of pups (D14). Adult rat brain was positive control. Data are mean $\pm S E M$ ( $n=5$ each). Values were normalized to $\beta$-actin. Vimentin and GFAP levels were elevated in pups with IVH compared with pups without IVH. Perampanel treatment did not affect GFAP or vimentin expression. ${ }^{*} p<0.05$, no IVH versus IVH. ** $p<0.01$, no IVH versus IVH. ${ }^{* * *} p<0.001$, no IVH versus IVH.

Together, our findings justify consideration of perampanel treatment in preterm infants with IVH.

We demonstrated that AMPA-kainate blockade suppressed inflammation. Specifically, we noted that NBQX treatment reduced apoptotic OPC death, microglia infiltration, and production of proinflammatory cytokines, including $T N F \alpha, I L 1 \beta, L I F$, and $I L-6$. It appears that NBQX treatment reduced cell death by attenuating $\mathrm{Ca}^{2+}$ levels in the OPCs and consequently diminished microglia infiltration in the white matter of rabbits with IVH. Importantly, microglia express GluR2-5, GluR7, KA1, and KA2 receptors; and activation of their Glu receptors triggers release of TNF- $\alpha$ (Noda et al., 2000; Hagino et al., 2004). Other proinflammatory cytokines (IL- $1 \beta$ and interferon- $\gamma$ ) are also produced primarily by microglia or T-lymphocytes in conditions of brain injury. LIF is an IL-6 class cytokine that inhibits cell differentiation. Hence, we speculate that downregulation of LIF, TNF $\alpha$, and IL1 $\beta$ with NBQX treatment might have promoted maturation of OPCs in rabbits with IVH
(Falahati et al., 2013; Rittchen et al., 2015). Because AMPA inhibition also blocks TNF $\alpha$ - and IL1 $\beta$-induced oligodendrocyte and neuronal death (Hermann et al., 2001; Takahashi et al., 2003), downregulation of cytokines by NBQX treatment in our rabbit pups might have reduced apoptosis of OPC after IVH. NBQX has been shown to induce protective hypothermia (Nurse and Corbett, 1996). However, we observed no difference in the rectal temperature between NBQX-treated and vehicle controls, which is consistent with the other studies (Hagberg et al., 1994; Follett et al., 2000). Thus, activation of AMPA receptors contributed to apoptotic cell death, microglial infiltration, and release of cytokines; and NBQX treatment seemingly ameliorated inflammation, reduced release of TNF $\alpha$ and IL- $1 \beta$ from microglia, and consequently enhanced survival and maturation of OPCs.

Composition of AMPA receptors, particularly the expression of GluR2 subunit, has a critical impact on AMPA-mediated toxicity, and the relative expression of the AMPA subunits alters during brain 
development and in brain pathologies (Pellegrini-Giampietro et al., 1992). AMPA receptor composition has been evaluated in the embryonic white matter of human fetuses and preterm infants of 18-46 gestational weeks (Talos et al., 2006a, b). GluR1 expression remains above adult level and does not change significantly with advance in gestational age. In contrast, GluR2 expression in the embryonic brain is $\sim 40 \%-60 \%$ of the adult level and gradually increases as gestational age advances. GluR3 and GluR4 levels are several-fold higher in preterm infants and gradually drops to adult level by the end of pregnancy. In the present study, we did not find any difference in the expression of GluR1-GluR4 in infants with and without IVH in our analyses of human samples. However, we made an important observation that GluR1 and GluR2 were significantly reduced in periventricular white matter and germinal matrix compared with the cortex. Because the presence of GluR2 subunit renders AMPA receptors impermeable to $\mathrm{Ca}^{2+}$, diminished expression of GluR2 in white matter and germinal matrix can increase their vulnerability to $\mathrm{Ca}^{2+}$-induced injury, unlike the cortical mantle. Conversely, a reduction in GluR1 expression will decrease $\mathrm{Ca}^{2+}$ permeability and diminish glutamate-induced excitotoxicity. Thus, the ratio of GluR1 and GluR2 expression in IVH is likely to determine the $\mathrm{Ca}^{2+}$ permeability and subsequent neurotoxicity.

JAK-STAT3 pathways regulate cell survival, proliferation, and differentiation (Aaronson and Horvath, 2002). They are active during periods of neuronal and glial differentiation and are stimulated by cytokines (Cattaneo et al., 1999). STAT3 is expressed by astrocytes and OPCs and plays a key role in mediating astrogliosis in models of spinal cord injury, traumatic brain damage, and cerebral infection (Na et al., 2007; Herrmann et al., 2008; Zhao et al., 2011). Accordingly, we found increased phosphorylation (tyrosine 705) and elevated total levels of STAT-3 in pups with IVH and restoration after NBQX treatment. However, NBQX treatment did not affect proliferation of astrocytes, GFAP expression, or the levels of transcription factors regulating astrocytes (NFIA and SOX9) in our model of IVH. Previous study in a paradigm of neuropathic pain has shown that JAK-STAT3 activation increases astrocyte proliferation. STAT-3 knock out animals also exhibit reduced GFAP expression in several models of brain injury (O'Callaghan et al., 2014). Coculture studies of neural stem cells and microglia have demonstrated that STAT-3 activation increases astrogliosis via Notch and Sox9 signaling pathway (Zhu et al., 2008). Together, AMPA blockade did not affect astrogliosis despite inhibition of STAT-3 signaling, which indicates that other signaling pathways (Notch, bone morphogenetic protein, or transforming growth factor $\beta$ ) might also be contributing to IVHinduced astrogliosis.

In conclusion, this study discovered previously an unknown role of AMPA-kainate receptors in IVH-induced hypomyelination and identified a novel strategy to restore myelination in the survivors of IVH. Reduced GluR2 expression in the OPCs of the white matter and germinal matrix likely contributed to their high propensity to IVH-induced injury. More importantly, AMPA-kainate inhibition by NBQX treatment suppressed inflammation, reduced apoptosis of OPCs, enhanced their maturation and myelination, and promoted neurologic recovery. AMPA receptor-specific inhibitor perampanel, an FDA-approved drug, was also found to restore myelination of the white matter and neurological function; therefore, perampanel treatment might improve the neurological outcome of preterm infants with IVH.

\section{References}

Aaronson DS, Horvath CM (2002) A road map for those who don't know JAK-STAT. Science 296:1653-1655. CrossRef Medline

Back SA, Luo NL, Borenstein NS, Levine JM, Volpe JJ, Kinney HC (2001)
Late oligodendrocyte progenitors coincide with the developmental window of vulnerability for human perinatal white matter injury. J Neurosci 21:1302-1312. Medline

Back SA, Han BH, Luo NL, Chricton CA, Xanthoudakis S, Tam J, Arvin KL, Holtzman DM (2002) Selective vulnerability of late oligodendrocyte progenitors to hypoxia-ischemia. J Neurosci 22:455-463. Medline

Ballabh P (2010) Intraventricular hemorrhage in premature infants: mechanism of disease. Pediatr Res 67:1-8. CrossRef Medline

Ballabh P, Xu H, Hu F, Braun A, Smith K, Rivera A, Lou N, Ungvari Z, Goldman SA, Csiszar A, Nedergaard M (2007) Angiogenic inhibition reduces germinal matrix hemorrhage. Nat Med 13:477-485. CrossRef Medline

Bystron I, Blakemore C, Rakic P (2008) Development of the human cerebral cortex: Boulder Committee revisited. Nat Rev Neurosci 9:110-122. CrossRef Medline

Cai Z, Lin S, Pang Y, Rhodes PG (2004) Brain injury induced by intracerebral injection of interleukin-1beta and tumor necrosis factor-alpha in the neonatal rat. Pediatr Res 56:377-384. CrossRef Medline

Cattaneo E, Conti L, De-Fraja C (1999) Signalling through the JAK-STAT pathway in the developing brain. Trends Neurosci 22:365-369. CrossRef Medline

Choi DW (1995) Calcium: still center-stage in hypoxic-ischemic neuronal death. Trends Neurosci 18:58-60. CrossRef Medline

Chua CO, Chahboune H, Braun A, Dummula K, Chua CE, Yu J, Ungvari Z, Sherbany AA, Hyder F, Ballabh P (2009) Consequences of intraventricular hemorrhage in a rabbit pup model. Stroke 40:3369-3377. CrossRef Medline

Dávalos A, Castillo J, Serena J, Noya M (1997) Duration of glutamate release after acute ischemic stroke. Stroke 28:708-710. CrossRef Medline

Deng W, Rosenberg PA, Volpe JJ, Jensen FE (2003) Calcium-permeable AMPA-kainate receptors mediate toxicity and preconditioning by oxygen-glucose deprivation in oligodendrocyte precursors. Proc Natl Acad Sci U S A 100:6801-6806. CrossRef Medline

Dohare P, Hyzinski-García MC, Vipani A, Bowens NH, Nalwalk JW, Feustel PJ, Keller RW Jr, Jourd'heuil D, Mongin AA (2014) The neuroprotective properties of the superoxide dismutase mimetic tempol correlate with its ability to reduce pathological glutamate release in a rodent model of stroke. Free Radic Biol Med 77:168-182. CrossRef Medline

Dummula K, Vinukonda G, Chu P, Xing Y, Hu F, Mailk S, Csiszar A, Chua C, Mouton P, Kayton RJ, Brumberg JC, Bansal R, Ballabh P (2011) Bonemorphogenetic protein inhibition promotes neurological recovery after intraventricular hemorrhage. J Neurosci 31:12068-12082. CrossRef Medline

Falahati S, Breu M, Waickman AT, Phillips AW, Arauz EJ, Snyder S, Porambo M, Goeral K, Comi AM, Wilson MA, Johnston MV, Fatemi A (2013) Ischemia-induced neuroinflammation is associated with disrupted development of oligodendrocyte progenitors in a model of periventricular leukomalacia. Dev Neurosci 35:182-196. CrossRef Medline

Fern R, Möller T (2000) Rapid ischemic cell death in immature oligodendrocytes: a fatal glutamate release feedback loop. J Neurosci 20:34-42. Medline

Follett PL, Rosenberg PA, Volpe JJ, Jensen FE (2000) NBQX attenuates excitotoxic injury in developing white matter. J Neurosci 20:9235-9241. Medline

Follett PL, Deng W, Dai W, Talos DM, Massillon LJ, Rosenberg PA, Volpe JJ, Jensen FE (2004) Glutamate receptor-mediated oligodendrocyte toxicity in periventricular leukomalacia: a protective role for topiramate. J Neurosci 24:4412-4420. CrossRef Medline

Gallo V, Patneau DK, Mayer ML, Vaccarino FM (1994) Excitatory amino acid receptors in glial progenitor cells: molecular and functional properties. Glia 11:94-101. CrossRef Medline

Geiger JR, Melcher T, Koh DS, Sakmann B, Seeburg PH, Jonas P, Monyer H (1995) Relative abundance of subunit mRNAs determines gating and $\mathrm{Ca} 2+$ permeability of AMPA receptors in principal neurons and interneurons in rat CNS. Neuron 15:193-204. CrossRef Medline

Georgiadis P, Xu H, Chua C, Hu F, Collins L, Huynh C, Lagamma EF, Ballabh $P$ (2008) Characterization of acute brain injuries and neurobehavioral profiles in a rabbit model of germinal matrix hemorrhage. Stroke 39: 3378-3388. CrossRef Medline

Gidal BE, Laurenza A, Hussein Z, Yang H, Fain R, Edelstein J, Kumar D, Ferry J (2015) Perampanel efficacy and tolerability with enzyme-inducing AEDs in patients with epilepsy. Neurology 84:1972-1980. CrossRef Medline

Goda M, Isono M, Fujiki M, Kobayashi H (2002) Both MK801 and NBQX 
reduce the neuronal damage after impact-acceleration brain injury. J Neurotrauma 19:1445-1456. CrossRef Medline

Groom AJ, Smith T, Turski L (2003) Multiple sclerosis and glutamate. Ann N Y Acad Sci 993:229-275; discussion 287-288. CrossRef Medline

Hagberg H, Gilland E, Diemer NH, Andiné P (1994) Hypoxia-ischemia in the neonatal rat brain: histopathology after post-treatment with NMDA and non-NMDA receptor antagonists. Biol Neonate 66:205-213. CrossRef Medline

Hagino Y, Kariura Y, Manago Y, Amano T, Wang B, Sekiguchi M, Nishikawa K, Aoki S, Wada K, Noda M (2004) Heterogeneity and potentiation of AMPA type of glutamate receptors in rat cultured microglia. Glia 47: 68-77. CrossRef Medline

Hanada T, Hashizume Y, Tokuhara N, Takenaka O, Kohmura N, Ogasawara A, Hatakeyama S, Ohgoh M, Ueno M, Nishizawa Y (2011) Perampanel: a novel, orally active, noncompetitive AMPA-receptor antagonist that reduces seizure activity in rodent models of epilepsy. Epilepsia 52: 1331-1340. CrossRef Medline

Hanada T, Ido K, Kosasa T (2014) Effect of perampanel, a novel AMPA antagonist, on benzodiazepine-resistant status epilepticus in a lithium-pilocarpine rat model. Pharmacol Res Perspect 2:e00063. CrossRef Medline

Hermann GE, Rogers RC, Bresnahan JC, Beattie MS (2001) Tumor necrosis factoralpha induces $\mathrm{cFOS}$ and strongly potentiates glutamate-mediated cell death in the rat spinal cord. Neurobiol Dis 8:590-599. CrossRef Medline

Herrmann JE, Imura T, Song B, Qi J, Ao Y, Nguyen TK, Korsak RA, Takeda K, Akira S, Sofroniew MV (2008) STAT3 is a critical regulator of astrogliosis and scar formation after spinal cord injury. J Neurosci 28:7231-7243. CrossRef Medline

Itoh T, Beesley J, Itoh A, Cohen AS, Kavanaugh B, Coulter DA, Grinspan JB, Pleasure D (2002) AMPA glutamate receptor-mediated calcium signaling is transiently enhanced during development of oligodendrocytes. J Neurochem 81:390-402. CrossRef Medline

Jackson A, Mead AN, Rocha BA, Stephens DN (1998) AMPA receptors and motivation for drug: effect of the selective antagonist NBQX on behavioural sensitization and on self-administration in mice. Behav Pharmacol 9:457-467. CrossRef Medline

Jensen FE (2005) Role of glutamate receptors in periventricular leukomalacia. J Child Neurol 20:950-959. CrossRef Medline

Juliet PA, Frost EE, Balasubramaniam J, Del Bigio MR (2009) Toxic effect of blood components on perinatal rat subventricular zone cells and oligodendrocyte precursor cell proliferation, differentiation and migration in culture. J Neurochem 109:1285-1299. CrossRef Medline

Kanwar JR, Kanwar RK, Krissansen GW (2004) Simultaneous neuroprotection and blockade of inflammation reverses autoimmune encephalomyelitis. Brain 127:1313-1331. CrossRef Medline

Kostic M, Zivkovic N, Stojanovic I (2013) Multiple sclerosis and glutamate excitotoxicity. Rev Neurosci 24:71-88. CrossRef Medline

Mouton PR, Chachich ME, Quigley C, Spangler E, Ingram DK (2009) Caloric restriction attenuates amyloid deposition in middle-aged dtg APP/ PS1 mice. Neurosci Lett 464:184-187. CrossRef Medline

Na YJ, Jin JK, Kim JI, Choi EK, Carp RI, Kim YS (2007) JAK-STAT signaling pathway mediates astrogliosis in brains of scrapie-infected mice. J Neurochem 103:637-649. CrossRef Medline

Noda M, Nakanishi H, Nabekura J, Akaike N (2000) AMPA-kainate subtypes of glutamate receptor in rat cerebral microglia. J Neurosci 20: 251-258. Medline

Nurse S, Corbett D (1996) Neuroprotection after several days of mild, druginduced hypothermia. J Cereb Blood Flow Metab 16:474-480. CrossRef Medline

O’Callaghan JP, Kelly KA, VanGilder RL, Sofroniew MV, Miller DB (2014) Early activation of STAT3 regulates reactive astrogliosis induced by diverse forms of neurotoxicity. PLoS One 9:e102003. CrossRef Medline

Ortega JA, Radonjić NV, Zecevic N (2013) Sonic hedgehog promotes generation and maintenance of human forebrain Olig2 progenitors. Front Cell Neurosci 7:254. CrossRef Medline

Pellegrini-Giampietro DE, Zukin RS, Bennett MV, Cho S, Pulsinelli WA (1992) Switch in glutamate receptor subunit gene expression in CA1 subfield of hippocampus following global ischemia in rats. Proc Natl Acad Sci U S A 89:10499-10503. CrossRef Medline

Pulsinelli WA, Brierley JB, Plum F (1982) Temporal profile of neuronal damage in a model of transient forebrain ischemia. Ann Neurol 11: 491-498. CrossRef Medline
Rittchen S, Boyd A, Burns A, Park J, Fahmy TM, Metcalfe S, Williams A (2015) Myelin repair in vivo is increased by targeting oligodendrocyte precursor cells with nanoparticles encapsulating leukaemia inhibitory factor (LIF). Biomaterials 56:78-85. CrossRef Medline

Rogawski MA (2011) Revisiting AMPA receptors as an antiepileptic drug target. Epilepsy Curr 11:56-63. CrossRef Medline

Rosenberg PA, Dai W, Gan XD, Ali S, Fu J, Back SA, Sanchez RM, Segal MM, Follett PL, Jensen FE, Volpe JJ (2003) Mature myelin basic proteinexpressing oligodendrocytes are insensitive to kainate toxicity. J Neurosci Res 71:237-245. CrossRef Medline

Russo E, Gitto R, Citraro R, Chimirri A, De Sarro G (2012) New AMPA antagonists in epilepsy. Expert Opin Investig Drugs 21:1371-1389. CrossRef Medline

Sehgal PB (2008) Paradigm shifts in the cell biology of STAT signaling. Semin Cell Dev Biol 19:329-340. CrossRef Medline

Takahashi JL, Giuliani F, Power C, Imai Y, Yong VW (2003) Interleukin1beta promotes oligodendrocyte death through glutamate excitotoxicity. Ann Neurol 53:588-595. CrossRef Medline

Talos DM, Fishman RE, Park H, Folkerth RD, Follett PL, Volpe JJ, Jensen FE (2006a) Developmental regulation of alpha-amino-3-hydroxy-5methyl-4-isoxazole-propionic acid receptor subunit expression in forebrain and relationship to regional susceptibility to hypoxic/ischemic injury: I. Rodent cerebral white matter and cortex. J Comp Neurol 497: 42-60. CrossRef Medline

Talos DM, Follett PL, Folkerth RD, Fishman RE, Trachtenberg FL, Volpe JJ, Jensen FE (2006b) Developmental regulation of alpha-amino-3hydroxy-5-methyl-4-isoxazole-propionic acid receptor subunit expression in forebrain and relationship to regional susceptibility to hypoxic/ ischemic injury: II. Human cerebral white matter and cortex. J Comp Neurol 497:61-77. CrossRef Medline

TanakaH,GroomsSY, BennettMV,Zukin RS (2000) TheAMPAR subunitGluR2: still front and center-stage. Brain Res 886:190-207. CrossRef Medline

Tekkök SB, Goldberg MP (2001) AMPA-kainate receptor activation mediates hypoxic oligodendrocyte death and axonal injury in cerebral white matter. J Neurosci 21:4237-4248. Medline

Vannucci RC, Brucklacher RM, Vannucci SJ (1999) CSF glutamate during hypoxia-ischemia in the immature rat. Brain Res Dev Brain Res 118: 147-151. CrossRef Medline

Vazquez B, Yang H, Williams B, Zhou S, Laurenza A (2015) Perampanel efficacy and safety by gender: subanalysis of phase III randomized clinical studies in subjects with partial seizures. Epilepsia 56:e90-e94. CrossRef Medline

Verdoorn TA, Burnashev N, Monyer H, Seeburg PH, Sakmann B (1991) Structural determinants of ion flow through recombinant glutamate receptor channels. Science 252:1715-1718. CrossRef Medline

Vinukonda G, Csiszar A, Hu F, Dummula K, Pandey NK, Zia MT, Ferreri NR, Ungvari Z, LaGamma EF, Ballabh P (2010) Neuroprotection in a rabbit model of intraventricular haemorrhage by cyclooxygenase-2, prostanoid receptor-1 or tumour necrosis factor-alpha inhibition. Brain 133:22642280. CrossRef Medline

Volpe JJ (2009a) Brain injury in premature infants: a complex amalgam of destructive and developmental disturbances. Lancet Neurol 8:110-124. CrossRef Medline

Volpe JJ (2009b) The encephalopathy of prematurity-brain injury and impaired brain development inextricably intertwined. Semin Pediatr Neurol 16:167-178. CrossRef Medline

Vose LR, Vinukonda G, Jo S, Miry O, Diamond D, Korumilli R, Arshad A, Zia MT, Hu F, Kayton RJ, La Gamma EF, Bansal R, Bianco AC, Ballabh P (2013) Treatment with thyroxine restores myelination and clinical recovery after intraventricular hemorrhage. J Neurosci 33:17232-17246. CrossRef Medline

Yoshioka A, Yamaya Y, Saiki S, Kanemoto M, Hirose G, Beesley J, Pleasure D (2000) Non- $N$-methyl-D-aspartate glutamate receptors mediate oxygenglucose deprivation-induced oligodendroglial injury. Brain Res 854: 207-215. CrossRef Medline

Zhao JB, Zhang Y, Li GZ, Su XF, Hang CH (2011) Activation of JAK2/STAT pathway in cerebral cortex after experimental traumatic brain injury of rats. Neurosci Lett 498:147-152. CrossRef Medline

Zhu P, Hata R, Cao F, Gu F, Hanakawa Y, Hashimoto K, Sakanaka M (2008) Ramified microglial cells promote astrogliogenesis and maintenance of neural stem cells through activation of Stat3 function. FASEB J 22: 3866-3877. CrossRef Medline 